\title{
A FIELD TEST FOR DYNMATIC SOIL PROPERTIES
}

\author{
G. L. Evans*
}

\section{Introduction}

The propogation velocity of waves through the ground has been used for many years in seismic surveys for the detection of underlying strata. From a knowledge of the percussion (P) and shear (S) wave velocities in different materials, together with their bulk densities, it is possible to derive dynamic moduli and properties, such as the shear nodulus (G) and poisson's ratio $(n)$, which are essential in the solution of problems relating to dynamic earth pressure, soil structure interaction and the dynamic analysis of foundation strata relating to earthquake engineering.

The principle involved in finding the wave velocities in ground materials is the same as used in finding velocities in any material. A simple wave form or pulse is generated at one point and the travel time to several other points is detected with suitable signal receivers.

For field work all equipment must be easily portable, self contained for power supply and reasonably robust.

The dynamic moduli of soils can be found in laboratory tests which have the advantage that strain can be controlled and measured accurately; this is important because $G$ is known to be strain dependent. The disadvantage of a laboratory test is that it $\mathrm{finds}$ the properties of only a very small sample of material. This is whare the field test has a primary advantage in that it averages out singll variations in the material and provides values which apply to a generally larger body of material. The disadvantage of the field test is the difficulty of controliing and measuring the strain applied to the ground during the test. Theoretically the strain can be determined from the ratio of the particle velocity over the wave propogation velocity(1) but the tests made so far in developing the method described below have not provided an absolute measure of the particle velocity, and honce the strains cannot be accurately found, although it is known that they are very small.

The detecting seismometers, al though very sensitive and effective for many dynamic measurements, were found to have a ringing frequency which completely disguised the true amplitudes of the ground pulse. Attempts have been made to correct this mathematically on the records of the instrumental response output, but this method cannot give any amplitude precision. An instrument without a ringing response at or near the ground pulse wave

* Senior Lecturer in Civil Engineering, University of Canterbury. frequencies is needed to complete this part of the work.

Despite these measurement difficulties, which were properly interpreted only after most of the field work had been done, the testing technique has shown -

(1) It is possible to obtain unique values of $V_{p}$ and $V_{s}$ for ground materials.

(2) From in situ densities and the velocities found, the appropriate values of elastic modulus, shear modulus, poisson's ratio can be calculated.

(3) The presence of sub surface strata changes can be inferred, but should in general be checked by drilling.

\section{Elastic Properties}

Derivation of the following relationships can be found in text books on elasticity (2). They are summarised here to show how test results can be applied。

$$
\begin{aligned}
& \mathrm{E}=\text { Youngs modulus of elasticity. } \\
& \mathrm{G}=\text { Modulus of rigidity or shear modulus. } \\
& \mathrm{n}=\text { Poisson's ratio. } \\
& \rho=\text { Density. } \\
& \lambda \text { and G are Lame's constants. }
\end{aligned}
$$

$$
\begin{array}{lll}
\mathrm{n}=\frac{\lambda}{2(\lambda+G)} \text { or } \lambda=\frac{2 \mathrm{G}}{1-2 \mathrm{n}} & \ldots \ldots(1) \\
\mathrm{G}=\frac{\mathrm{E}}{2(1+n)} \text { or } \mathrm{E}=2(1+\mathrm{n}) \mathrm{G} & \ldots \ldots(2)
\end{array}
$$

From equations of motion and the solution of the wave equation the seismic wave velocities can be found as (2).

Primary or percussion wave speed

$$
V_{\dot{p}}=\left(\frac{\lambda+2 G)^{\frac{1}{2}}}{\rho}\right.
$$

Secondary or shear wave speed

$$
\begin{gathered}
V_{s}=\left(\frac{G}{\rho}\right)^{\frac{1}{2}} \ldots \ldots \\
\text { It follows that } G=\rho V_{s}^{2} \\
2 .
\end{gathered}
$$

And in 1b.sec.units

$$
G=\frac{W}{g} \frac{V_{s}}{144} 1 b s / s q \text {.in. }
$$

Where $W=$ bulk density (in lbs/coft.) and $\rho=\frac{W}{g}$ 
From (3) and (4) with the substitution from (1) it can be shown that -

$$
\begin{array}{r}
V_{s}=\left(\frac{1-2 n}{2(1-n)}\right)^{\frac{1}{2}} \times V_{p} \\
\text { From which } n=\frac{V_{r}^{2}-2}{2(V / 2-1)}
\end{array}
$$

Where $\mathrm{V}_{r}=\frac{\mathrm{Vp}_{\mathrm{p}}}{\mathrm{V}_{\mathbf{s}}}$

With field test results for $V_{s}$ and $V_{p}$ used in equations (6), (8) and (9), values can be found for $G$ and $n$ and then from equation (2) the value of $E$.

The values of $V_{s}$ depend on $G$ as seen in equation (5). The shear modulus (G) has been found to be strajn dependent in soils and is also closely related to void ratio, moisture content, and to a lesser extent is influenced by other factors such as rrequency of wave motion and confining pressure (3) (4).

It seems very Iikely that the shear wave velocity ( $\mathrm{V}_{\mathrm{S}}$ ) in soil materials would be affected also by strain level, void ratio and moisture content.

\section{Test Method}

The layout of equipment is similar to that used in seismic surveys but on a much reduced scale: The signal, either a $P$ wave or $S$ wave pulse, is transmitted a distance of up to 100 ft depending on the amount of ground absorption Signal detectors are located at $10 \mathrm{ft}$ intervals from the signal source.

If sufficient detectors could be used all the data could be collected from one pulse signal with all the detected signals received into a multi channel recorder. Only two sensitive seismometers were available, so the tests were done using a series of signals with the seismometers being moved further away each time.

In general for a uniform material unique values for $V_{S}$ and $V_{p}$ were found. In the example considered later where the material was initially thought to be uniform, a variety of velocities were letected and these formed the basis of a depth study of stratification. In addition 3 ft diameter holes were bored for inspection, sampling and subsurface velocity tests.

When the signal generator was used for an $S$ wave pulse in uniform material, the predominant signal received was an $\mathrm{S}$ wave although a small amplitude of $P$ wave was also recorded. However when the material shows stratification a reflected $P$ wave can return as an $S$ wave (5). The $P$ and $S$ waves are usually obvious when the records are analysed because the wave velocities $V_{p}$ and $V_{s}$ are quite different.

In stratified material waves may be refracted after travelling some distance in the lower material. The geometry of this is illustrated in Appendix I. Alternatively the wave may be simply reflected and travel entirely in the top strata (See Appendix II). If this occurs the reflected wave from an original P wave may be both $S$ and $P$ wave. Hence the velocity calculated for a mixed return wave (e.g. half the journey as $P$ wave and returning as an $S$ wave) will be rather lower than the true $P$ wave velocity. The true $P$ wave velocity can be found from the measured $S$ wave velocity and the "average" ( $\mathrm{S}+\mathrm{P})$ velocity as shown in Appendix III.

\section{Apparatus}

(1) The signal generator is a compound pendulum impacting on a $4 \mathrm{ft}$ long steel bar ( 4 " $\mathrm{x} 2$ " hollow section) keyed to the ground. This is triggered by a magnetically released pin operated by a remote push button at the recording set. Different impact intensities can be selected by setting the start position of the pendulum at different levels. The time of impact is transmitted from a contact at the point of impact, and this is recorded with other timed data. Two impact intensities were generally used: these were (2) and (4). The values are arbitrary but impact (4) is greater than impact (2)。

(2) Wilmore Seismometers Mk II (S.G.450) detected the ground wave impulse. These seismo meters were mounted on triangular three pronged bases driven into the ground about six inches. The signals from the seismometers were transmitted through cables to a six channel amplifier.

(3) The amplifier was made to match (on two circuits) the seismometers to provide the correct electrical damping to give 0.6 critical damping. The amplifier channels each have five stages of amplification with ranges 0 - (no gain), $1-(x 2.55$ gain $), 2-(x 17.69$ gain $)$, $3-(x 35.8$ gain $), 4-(x$ (x 4.8 gain $), 5-(x$ 276 gain). It was found that a gain of (2) was generally adequate, but sometimes (0) or (1) was needed for low loss materials.

Generally gains of $(3),(4)$ and (5) registered too much microtremor vibration which interfered with the test signal, or these amounts of amplification put the test signals off scale. This amplifier was built in the electronics section of the Civil Engineering Department of the University of Canterbury.

(4) The amplified signal was recorded by a Kyowa "Rapet" recorder having a travelling paper chart with speeds of $5,10,50,100 \mathrm{cms} /$ sec. A speed of $50 \mathrm{cms} / \mathrm{sec}$. was found most suitable for field work. This recorder has an incandescent light source and the signal trace is recorded by a light beam from miniature galvonometers. Special paper is used which can be semi developed by exposure to a fluorescent light for initial examination. Permanising with chemical intensifier and fixer can be done later if needed. The paper is stable in dim light or artificial light even before fixing。

(5) A small 12 volt motorcycle battery was the power source for the Rapet recorder and the magnetic release. Sometimes this was supplemented with a lead to the battery in the car engine.

The apparatus is essentially quite simple and easy to use, but experience has shown that further improvements could be made, particularly to the triggering device and the type of signal detector。

\section{(5) Types of Ground Tested}

To obtain a range of results the field test 
178

has been applied to the several sites including the following.

1. Gravel at the University field station at Shipleys Road, Christchurch.

2. Sand at New Brighton.

3. Silty clay at IIam University where it overlies sand and gravel at about $10 \mathrm{ft}$.

4. Saturated silty clay at Heathcote Valley, Christchurch.

5. Loess clay at Glenmore brickworks, Port Hills Road, Christchurch.

This last test included sub surface tests and is described in detail below.

The results from these tests are shown in Table I which lists the measured values of $V_{S} \&$ $V_{p}$ with other deduced dynamic properties.

\section{The Glenmore Brickworks Test}

\section{(1) The Site}

Geological data was available from a previous investigation done in 1966 by N.Z. Geological Survey Section of D.S.I.R. in Christchurch. The area is on a fairly steeply sloping hilside and access for vehicles governed the location of a test area. The cross section of the site is shown in Figure 1. The geological evidence indicated a good depth of loess of a generally uniform nature except for slight moisture variations. The rock sides of the valley were sufficiently remote to eliminate unwanted reflections and the previous seismic survey indicated an interface at a depth of about $40 \mathrm{ft}$.

\section{(2) Installation and Layout}

On a reasonably level area a line was set at $345^{\circ} \mathrm{Mg}$ and pegged at $10 \mathrm{ft}$ intervals for 80 ft. The sequence of test is shown in figure 2 . This shows diagrammatically the arrangement and direction of the impact pendulum and instrument bases in plan view.

Two series of tests were made on the ground surface; the first for $S$ wave pluses with lateral orientation of the impact pendulum and the seismometers, and the second for $P$ wave pulses with the impact pendulum and seismometers orientated longitudinally。

Following the surface tests, sub surface tests were made in holes bored to $11 \mathrm{ft}$ and extended to $20 \mathrm{ft}$ at pegs $30,50,60,70 \mathrm{ft}$. These holes were $3 \mathrm{ft}$ in diameter and were just large enough to set equipment in albeit a little cramped. They were dug with a Calweld rig having a rotating cutter bucket. Down to 20 ft there was no problem with wall collapse and no linings were used.

The down hole tests were made to check the data inferred from the surface tests and also to get in situ densities and obtain samples for moisture content tests and other physical checks.

It proved very much more difficult and slower setting up tests in the holes, particularly when moisture and dirt prevented the impact pendulum from triggering properly which meant repeated trips down the hole on a winch rope to re-set th trigger。
The sequence of drilling was arranged so that the first test at 11 ft was made with unly two holes drilled $40 \mathrm{ft}$ apart (at $30 \mathrm{ft}$ peg and $70 \mathrm{ft}$ peg). This eliminated the possibility of interference from the in between holes. When other holes were drilled there appeared to be no significant change caused by interference with $S$ wave pulses, but at the $20 \mathrm{ft}$ level, an anomaly occured with the $P$ wave pulse. The hole at peg $60 \mathrm{ft}$ was masked in some way by the hole at peg $50 \mathrm{ft}$ as only a very small amplitude signal was received at peg 6́o hole. The signal at peg 70 was much bigger.

At the conclusion of the wave pulse tests the hole at peg 70 was deepened to find the interface indicated on the geological section. Wet conditions were encountered below $35 \mathrm{ft}$. and drilling had to be stopped at $41 \mathrm{ft}$ because the walls at this level were caving in with flowing water.

Samples were taken at $5 \mathrm{ft}$ intervals down this hole and the results of density and moisture tests are shown in $\mathrm{T}_{\mathrm{a}} \mathrm{ble}$ II and in figure 3. Below about 40 feet the saturated material was soft and a probe was pushed down to $55 \mathrm{ft}$ without finding any rock although there seemed to be hard and soft layers.

The relative hardness values shown in figure 3 were obtained from a soiltest pocket penetrometer. This was pushed on to the sides of the hole at one foot intervals down to 35 ft. The pressure applied was almost to the maximum value of the instrument. The depth of indentation was estimated and this varied from less than $1 / 32$ nd of a inch to about $\frac{1}{4}$ inch. This method of measurement is somewhat arbitrary but does give an indication of relative hardness changes. The scale of hardness was obtained by inverting the fractions of an inch indentation and dividing by 4 , thus giving a range of 1 to 8 from soft to hard.

\section{(3) Test Procedure}

For each test the pendulum was released by the push button at the same time as the Rapet recorder was started. At a speed of $50 \mathrm{cms} / \mathrm{sec}$. about 12 inches of paper is needed to get a record, and about half this length is taken up with the recorder accelerating to about its right speed. Time pips automatically recorded on the paper at $1 / 100$ th second intervals overcame any problems with paper speed variation. Actual speeds during recording varied between $40 \mathrm{~cm} / \mathrm{s}$ and $60 \mathrm{~cm} / \mathrm{s}$, but were generally around about the design speed of 50 $\mathrm{cm} / \mathrm{s}$. For a short run the recorder must be stopped about half a second after starting. This could be done with a timer device (as an improvement) but for simplicity the stop button was hand operated. After a little practice and a "feel" for the time required, the right amount of paper could be passed without too much waste. The exposed paper was semi developed (photolysed) under a battery operated fluorescent lamp to see if a successful result was achieved.

On the surface tests two impact values (2) and (4) were used to find out if the magnitude of the pulse had any influence on the velocities. For the down hole tests impact (4) was generally used as the transmitted signal from impact (2) was attenuated more quickly and the received signals were not sufficient. 


\section{(4) Seisinometer Response}

The seismometers are supposed to be undirectional and respond only to a signal along the main axis. There is, however, a small response to signals at right angles to the axis. This means that both $P$ and. $S$ waves get recorded together, but these can generally be identified by the magnitude on the record and the calculated velocity.

The response of the seismometers to a sharp small tap is not a single spike type of signal but it is an attenuating oscillation as shown in figure 4. The frequency of this oscillation is a function of the instrument and the ground coupling or firmness of the base. After an initial impact or pulse is received the "ringing" oscillation effectively forms a base on which all other arriving impulses are superimposed. Changes in the wave trace show the position and time of arrival of later pulses but the amplitude of the signal cannot be determined. Figure 5 shows a typical record where times are shown on each trace for the initial arrival ( $P$-small) and the main $S$ wave beginning, followed by some later arrival waves.

\section{(5) Results}

The surface tests results are summarised in Tables III and IV in which are shown the distance travelled by the wave pulse and the time of arrival from impact point. The squared values of distance and time are also included in the tables as these values were plotted for the reflected wave analysis. The graphs of $T$ against $D$ for the refractive method are shown in figures 6 to 7 , and for the reflective plot in figures 9 and 10 . Figures 8 and 11 show the refractive and reflective plot for the $P$ wave pulse on the surface.

In addition to the first arrivals of the $P$ and $S$ waves it was possible on the longer distance records to identify a late wave arrival as a disturbance in the instrument response oscillation (see figure 5). These values are listed in Table $\mathrm{V}$ and graphed in figure 12 as a reflective plot.

The $S$ wave tests made at $11 \mathrm{ft}$ deep are listed in Table VI and graphed in figures 13 and 15. No $P$ wave tests were taken at $11 \mathrm{ft}$, but the results for the $S$ wave pulse show that $\mathrm{P}$ wave velocities were being recorded. Although the instruments were oriented to transmit and receive $S$ waves it seems that the influence of the holes created a $\mathrm{P}$ wave from the originating $S$ wave impulse and caused this to be recorded quite strongly with instruments oriented for $S$ waves. Both $S$ and $P$ wave pulse tests were made at $20 \mathrm{ft}$. These results are given in Tables VII and VIII and plotted in figures 14, 16, 17, 18. At this depth both $P$ and $S$ waves were recorded from the $S$ wave impulse, but only $S$ wave velocities were found from the $P$ wave test, Again it seems that the presence of the hole in some way caused a rotation of the initiated wave (from $P$ to S). This phenomena has not been investigated any further.

\section{(6) Interpretation of Results}

(i) The wave velocity data has been plotted in two ways.

(a) As a refracted wave graph illustrated in Appendix I. (b) As a reflected wave describad in Appendix II

The same values of time and distance are used in each method, but only in the direct arrival wave is the velocity found to be the same in each method. Which method should apply for the return waves is not easy to decide in some cases. The material has no sharp discontinuities, but there are distinct density changes revealed from the physical tests. Also the reflective method (Appendix II) leads to indicated layer depths which agree in general with the density and moisture changes.

\section{(ii) Surface Tests}

These are plotted by the refractive method in figures $6,7,8$ which indicate a higher velocity layer at $7 \mathrm{ft}$ to $10 \mathrm{ft}$. Apart from a small change in moisture between $5 \mathrm{ft}$ and $10 \mathrm{ft}$ (figure 3) there is little evidence to support this. The shear wave velocity for impact (2) shows two values $\left(V_{S}=550 \mathrm{ft} / \mathrm{s}\right.$. and $\left.765 \mathrm{ft} / \mathrm{s.}\right)$ which compare with the velocity $\left(V_{s}=620\right)$ from the impact (4) tests. Although not convincing there is here small evidence that different impact values create different velocities.

The same surface test data is plotted by the reflective method and shown in figures 9, 10, 11. The "average" reflective velocities of $725 \mathrm{ft} / \mathrm{sec}$. in figure 9 and $860 \mathrm{ft} / \mathrm{sec}$. in figure 10 seem to be too high to be $S$ waves and not high enough to be $P$ waves when the direct $S$ wave velocities are $550 \mathrm{ft} / \mathrm{sec}$. and $625 \mathrm{ft} / \mathrm{sec}$. If the reflected wave velocity is considered in this case as a $P$ wave travelling down and reflecting as an $S$ wave, the method of Appendix III can be applied and the $P$ wave velocities calculated as $1065 \mathrm{ft} / \mathrm{sec}$. and $1385 \mathrm{ft} / \mathrm{sec}$. respectively. These compare with the lower of the $P$ wave values $\left(V_{p}=1440\right)$ found in figure 11 .

From this method the following information can be inferred.

1. Upper layer $\mathbf{S}$ wave velocity $550-620$

Average

$$
550-620
$$

2. Upper layer $P$ wave velocity 1065-1380

3. A reflective layer exists at 14 to $16 \mathrm{ft}$, which agrees reasonably with the physical data in figure 3 .

\section{(iii) Down Hole Tests}

Because of the Iimitations on the number of holes, the results from these tests are rather limited, but some comparative information can be deduced.

At $11 \mathrm{ft}$ deep the tests shown in figure 13 indicate an increased shear wave velocity $\left(V_{S}=850\right)$ which is consistent with an increase in density just below $10 \mathrm{ft}$. This value of shear wave velocity is also close to that found from the late arrival waves in the surface tests illustrated in figure $12\left(V_{S}=913 \mathrm{ft} / \mathrm{sec}.\right)$.

Although no $P$ waves tests were made at 11 ft the records for $S$ wave tests give wave arrivals with $P$ wave velocity.

At $20 \mathrm{ft}$ deep the $\mathrm{S}$ wave graph, figure 14 , 
180

indicates a shear wave velocity of $900 \mathrm{ft} / \mathrm{sec}$. and a lower strata velocity of $1650 \mathrm{ft} / \mathrm{sec}$. but there is no physical evidence of this strata. The reflective plot in figure 16 shows similar $S$ wave velocity and a reflective laytr which agrees with a change in density。

The $P$ wave velocity is a little lower in this layer $(20-27 \mathrm{ft})$ with $V_{p}=1300$ to $1500 \mathrm{ft} /$ sec

The $P$ wave tests in figure 17 and 18

indicate $S$ wave relocities.

The deductions from the down hole tests can be summarised as:

$$
11 \mathrm{ft} \quad 20 \mathrm{ft}
$$

$$
\begin{array}{lrr}
S \text { wave velocity } & 850 & 925 \\
P \text { wave velocity } & 1580 & 1700
\end{array}
$$

A reflective layer exists at $25-27 \mathrm{ft}$; this could be a change in density and saturation level, as shown in figure 3 .

It is difficult to know how far to take the finer interpretation of some of the down hole results but figures 15 and 16 present interesting data for speculation. In figure 15 two alternative velocity lines are shown for $V_{2}$. This gives $P$ wave velocities of $1250 \mathrm{ft} / \mathrm{sec}$ and $1380 \mathrm{ft} / \mathrm{sec}$. The first of these is through the origin (as is $V_{3}=1660$ ) and is therefore not a reflected wave; and the second indicates a reflecting layer at (11 ft $+7 \mathrm{ft}=18 \mathrm{ft}$. With a shear wave $V_{S}=856 \mathrm{ft} / \mathrm{sec}$ and density values from figure 3 the derived properties in Table $\mathrm{X}$ are deduced.

According to these wave reflections there is a relatively hard layer at $11 \mathrm{ft}$ and a soft layer close to it. The relative hardness profile indicates that this could be so with a hard band between $10 \mathrm{ft}$ and 12 feet. The velocity reflection from $18 \mathrm{ft}$ could correspond to the hard layer found between $14 \mathrm{ft}$ and 18 $f t$. In figure 16 two velocities appear to be reflected from one hard layer at about $27 \mathrm{ft}$. Taken separately these gave the results shown in the last two Iines of Table $x$.

When compared with the more general deductions given in Table IX the analysis to a finer degree does not greatly alter the values found for $G$ and $E$.

\section{Derived Propperties}

The relationship between $n, V_{S}$ and $V_{p}$ given in section 2, is plotted in figure 19 and the equations relating $G, V_{S}$ and $W$ are plotted on the chart in figure 20. The se can be used to deduce the values of the elastic properties from the velocity data and densities found from tests. The calculation for $E$ is from equation ( 2 ).

In table IX all the values of $V_{S}, V_{p}$ and density are tabulated together with the derived properties。

The surface layer properties would apply for about $14 \mathrm{ft}$ as revealed by changes shown in figure 3. The second layer between $14-20 \mathrm{ft}$ has a higher and relatively uniform density and moisture content. Below $20 \mathrm{ft}$ the density increases steadily to $25 \mathrm{ft}$ and moisture increases to $25 \mathrm{ft}$ after which it is fairly stable at saturation. The bottom layer values apply at about $20 \mathrm{ft}$ to $25 \mathrm{ft}$, but sampling down to $35 \mathrm{ft}$ revealed a continuation of the very hard saturated material. It would be reasonable to use the same property values down to this depth.

The moisture content shows a slight increase between $35 \mathrm{ft}$ and $40 \mathrm{ft}$ which could indicate a decrease in density. This is consistent with the fact that the hole walls were soft and collapsed at a depth of about $41 \mathrm{ft}$ and a rod probe was pushed down to a depth of $55 \mathrm{ft}$ below the surface.

\section{Conclusions}

This investigation of the loess material was intended to reveal the characteristics of a uniform material and compare results from surface tests with down hole tests. It has in fact shown that the loess is stratified in density and moisture and the se changes can be detected by the pulse wave method. Tile main purpose of this field test was to deduce the elastic properties of the ground material and it has been shown that with additional information from a large bore hole, these properties $c$ an be found. When applied to other materials (e.go gravel and sand etc.) of a uniform nature, the different values of the elastic properties found are quite distinct and characteristic of the material。 The moduli found by this method are related to very small strains and for greater strain the values would be smaller.

\section{References}

(1) Kobayashi, "Mechanism of Earthquake Damage to Embankments and Slopes" - 4th World Conference on Earthquake Engineering 1969 .

(2) Jaeger, J. C. "Elasticity, Fracture and Flow" - Methven and Co.2nd Ed. 1962.

(3) Duke, C. M. "Techniques for Field Measurement of Shear Wave Velocities in Soils" - 4th World Conference on Earthquake Engineering 1969.

(4) Chae, Y. S. "Material Constants of Soils as determined from Dynamic Testing" Proc. Int. Symp. Wave Propogation and Dynamic Properties of Earth Materials 1964.

(5) Bullen, K. E. "An Introduction to the Theory of Seismology = p.105 - Cambridge University Press 3rd ed. 1963. 
TABLE I

\begin{tabular}{|l|c|c|c|c|c|c|c|}
\hline Material & $\begin{array}{l}\text { Density } \\
\text { lbs/c.ft. }\end{array}$ & $V_{s}$ & $V_{p}$ & $V_{p} / V_{s}$ & $n$ & G p.s.i. & E p.s.i. \\
\hline 1. Gravel & 120 & 750 & 1240 & 1.65 & .21 & 14,500 & 35,000 \\
2. Sand & 100 & 355 & 535 & 1.5 & .1 & 2,700 & 6,000 \\
3. Ilam Clay & 115 & 375 & 800 & 2.15 & .363 & 3,400 & 9,300 \\
4. Sat. Silty & 109 & 275 & 550 & 2 & .33 & 1,470 & 3,900 \\
\hline
\end{tabular}

TABLE II

Density and Moisture Changes

\begin{tabular}{|l|l|l|l|l|l|l|l|l|l|l|}
\hline \multicolumn{1}{|c|}{ Depth } & \multicolumn{3}{|c|}{ Density lbs/c.ft. } & \multicolumn{5}{c|}{ Moisture \% } \\
\hline Ft Peg & 0 & 30 & 50 & 60 & 70 & 0 & 30 & 50 & 60 & 70 \\
\hline $1-2$ & 138 & & 120 & & 112 & 8.2 & & 8.4 & & \\
\hline 5 & & & & & 107.4 & & & & & 12.3 \\
\hline 10 & & & & & 108.5 & & & & & 10.2 \\
\hline 11 & & 115 & & 114.5 & & & 13.5 & & 12.0 & \\
\hline 15 & & & & & 121.3 & & 12.7 & & & 15.2 \\
\hline 20 & & 110 & 114 & & 120.5 & & 14.2 & 14.17 & & 14.7 \\
\hline 25 & & & & & 124.4 & & & & & 21.7 \\
\hline 30 & & & & & 126.5 & & & & & 22.1 \\
\hline 35 & & & & & 128.8 & & & & & 22.5 \\
\hline 40 & & & & & & & & & & \\
\hline 41 & & & & & & & & & & 24.1 \\
\hline
\end{tabular}


TABLE III

Surface Tests: S Wave Pulse

Impact (2)

Impact (4)

\begin{tabular}{|c|c|c|c|c|c|c|c|}
\hline Test No. & D ft. & $D^{2}$ & T sec. & \multicolumn{1}{|c|}{$T^{2}$} & Test No. & secs & $T^{2}$ \\
\hline \multirow{3}{*}{82201} & 10 & 100 & .01395 & $1.946 \times 10^{-4}$ & 84201 & .01465 & $2.15 \times 10^{-4}$ \\
& 20 & 400 & .0259 & $6.71 \times 10^{-4}$ & & .02915 & $8.49 \times 10^{-4}$ \\
$82203 \mathrm{~A}$ & 30 & 900 & .0496 & $24.6 \times 10^{-4}$ & 84202 & .0505 & $25.5 \times 10^{-1}$ \\
& 40 & 1600 & .0637 & $40.57 \times 10^{-4}$ & & .0608 & $39.4 \times 10^{-4}$ \\
$82203 \mathrm{C}$ & 50 & 2500 & .0838 & $70.2 \times 10^{-4}$ & $84203 \mathrm{~A}$ & .0801 & $64.2 \times 10^{-4}$ \\
& 60 & 3600 & .109 & $118.8 \times 10^{-4}$ & & .0946 & $89.5 \times 10^{-4}$ \\
82204 & 50 & 2500 & .0705 & $49.7 \times 10^{-4}$ & $84203 B$ & .0701 & $49.1 \times 10^{-4}$ \\
& 60 & 3600 & .0801 & $64.2 \times 10^{-4}$ & & .0796 & $63.4 \times 10^{-4}$ \\
& 70 & 4900 & .0924 & $85.4 \times 10^{-4}$ & 84204 & .0863 & $74.5 \times 10^{-4}$ \\
& 80 & 6400 & .1029 & $105.8 \times 10^{-4}$ & & .1027 & $105.5 \times 10^{-4}$ \\
\hline
\end{tabular}

See Figure Nos. 6

9

7

10

TABLE IV

Surface Tests: P Wave Pulse

(Impact (4)

\begin{tabular}{|c|c|c|c|c|}
\hline Test No. & D ft & $D^{2}$ & $T \sec$ & $T^{2}$ \\
\hline $8410 \%$ & 10 & 100 & .0234 & $5.47 \times 10^{-4}$ \\
& 20 & 400 & .0747 & $55.8 \times 10^{-4}$ \\
84106 & 1600 & .0357 & $12.72 \times 10^{-4}$ \\
& 50 & .04125 & $17.0 \times 10^{-4}$ \\
84105 & 70 & 4900 & .0489 & $23.8 \times 10^{-4}$ \\
& 80 & 6400 & .0551 & $30.35 \times 10^{-4}$ \\
\hline
\end{tabular}


TABLE V

Surface Tests : Late Arrivals, P Wave Pulse

\begin{tabular}{|c|c|c|c|c|}
\hline Test No. & $D f t$ & $\mathrm{D}^{2}$ & $T$ sec & $T^{2}$ \\
\hline 84106 & $\begin{array}{l}40 \\
50 \\
70\end{array}$ & $\begin{array}{l}1600 \\
2500 \\
4900 \\
6400\end{array}$ & $\begin{array}{l}.0807 \\
.1370 \\
.0805 \\
.1190 \\
.090 \\
.1357 \\
.099 \\
.1370\end{array}$ & $\begin{array}{l}6.5 \times 10^{-3} \\
18.76 \times 10^{-3} \\
6.48 \times 10^{-3} \\
14.15 \times 10^{-3} \\
8.1 \times 10^{-3} \\
18.44 \times 10^{-3} \\
9.8 \times 10^{-3} \\
18.76 \times 10^{-3}\end{array}$ \\
\hline
\end{tabular}

See Figure No.

12

TABLE VI

Down Hole Tests : $11 \mathrm{ft}$ : S Wave Pulse

First Arrival

Second Arrival

\begin{tabular}{|c|c|c|c|c|c|c|}
\hline Test No. & D ft & $D^{2}$ & $T 1$ sec & $T 1^{2}$ & $T 2 s e c$ & $T 2^{2}$ \\
\hline 84210 & 20 & 400 & .012 & $1.44 \times 10^{-4}$ & .0160 & $2.56 \times 10^{-4}$ \\
84209 & 30 & 900 & .0186 & $3.24 \times 10^{-4}$ & .024 & $5.76 \times 10^{-4}$ \\
84208 & 400 & 1600 & .0304 & $9.25 \times 10^{-4}$ & .0239 & $5.71 \times 10^{-4}$ \\
82206 & 40 & 1600 & .0308 & $9.5 \times 10^{-4}$ & .04916 & $24.19 \times 10^{-4}$ \\
\hline
\end{tabular}


TABLE VII

Down Hole Tests: $20 \mathrm{ft}:$ S Ware Pulse

First Arrival Second Arrival

\begin{tabular}{|c|c|c|c|c|c|c|}
\hline Test No & D fl & $D^{2}$ & T1sec & T1 & T2sec & $T^{2}$ \\
\hline 84211 & 20 & 400 & .0157 & $2.465 \times 10^{-4}$ & .0188 & $3.535 \times 10^{-4}$ \\
& 30 & 900 & .02645 & $6.99 \times 10^{-4}$ & & \\
84212 & 30 & 900 & .022 & $4.84 \times 10^{-4}$ & .0334 & $11.66 \times 10^{-4}$ \\
& & & .0251 & $6.30 \times 10^{-4}$ & & \\
& \multirow{3}{*}{40} & \multirow{2}{*}{1600} & .0279 & $7.78 \times 10^{-4}$ & .0446 & $19.9 \times 10^{-4}$ \\
& & & .0323 & $10.44 \times 10-4$ & & \\
\hline
\end{tabular}

Soe Figure Nos. 14 16 14 16

TABLE VIII

Down Hole Tests : $20 \mathrm{ft}:$ P Ware Pulse

\begin{tabular}{|c|c|c|c|c|}
\hline Test $\mathrm{No}$ & $\mathrm{D} f \mathrm{ft}$ & $\mathrm{D}^{2}$ & $\mathrm{Tsec}$ & $\mathrm{T}^{2}$ \\
\hline \multirow{2}{*}{84114} & 20 & 400 & .0212 & $4.5 \times 10^{-4}$ \\
& 30 & 900 & .0339 & $11.5 \times 10^{-4}$ \\
\multirow{3}{*}{84113} & 90 & .0335 & $11.2 \times 10^{-4}$ \\
& 40 & 1600 & .0413 & $17.06 \times 10^{-4}$ \\
\hline
\end{tabular}


TABLE IX

Summary of Properties

\begin{tabular}{|c|c|c|c|c|c|c|c|}
\hline $\begin{array}{c}\text { Depth } \\
\text { ft }\end{array}$ & $\begin{array}{l}\text { Density } \\
\text { lbs/c.ft }\end{array}$ & $\begin{array}{l}\mathrm{V}_{\mathrm{S}} \\
\mathrm{ft} / \mathrm{sec}\end{array}$ & $\begin{array}{l}\mathrm{V}_{\mathrm{p}} \\
\mathrm{ft} / \mathrm{sec}\end{array}$ & $\mathrm{Vr}={ }^{\mathrm{V}} \mathrm{p} / \mathrm{V}_{\mathrm{s}}$ & $\begin{array}{l}n \\
-\end{array}$ & $1 \mathrm{bs} / \mathrm{sq} \cdot \mathrm{in}$ & Ibs/sq. in \\
\hline $\begin{array}{l}0 \text { to } \\
14 \mathrm{ft} .\end{array}$ & 108 & 585 & 1200 & 2.05 & 0.34 & 7,800 & 21,000 \\
\hline $\begin{array}{lll}14 & \mathrm{ft} & \mathrm{to} \\
20 & \mathrm{ft} & \end{array}$ & 121 & 850 & 1600 & 1.855 & 0.3 & 18,000 & 46,800 \\
\hline$\left|\begin{array}{lll}20 & \mathrm{ft} & \mathrm{to} \\
35 & \mathrm{ft} & \end{array}\right|$ & 125 & 915 & 1400 & 1.53 & 0.15 & 22,000 & 53,000 \\
\hline
\end{tabular}

TABLE $X$

\begin{tabular}{|c|c|c|c|c|c|c|c|}
\hline $\begin{array}{l}\text { Depth } \\
\text { ft }\end{array}$ & $\begin{array}{c}\text { Density } \\
1 \mathrm{bs} / \mathrm{c} \cdot \mathrm{ft} \text {. }\end{array}$ & $\begin{array}{c}\mathrm{V}_{\mathrm{s}} \\
\mathrm{ft} / \mathrm{sec}\end{array}$ & $\mathrm{ft}_{\mathrm{p}}^{\mathrm{p}} \mathrm{sec}$ & $v_{p} v_{p} / v_{s}=$ & $\mathrm{n}$ & $\frac{\mathrm{G}}{1 \mathrm{bs} / \mathrm{sq} \cdot \mathrm{in} .}$ & $1 \mathrm{bs} / \mathrm{sq} \cdot \mathrm{in}$. \\
\hline \multirow[t]{2}{*}{11} & \multirow[t]{2}{*}{109} & 856 & 1250 & 1.46 & 0.1 & 17,000 & 37,400 \\
\hline & & 856 & 1660 & 1.915 & 0.32 & 17,000 & 45,000 \\
\hline $11-18$ & 120 & 856 & 1380 & 1.61 & 0.15 & 18,000 & 41,400 \\
\hline \multirow[t]{2}{*}{$20-27$} & \multirow[t]{2}{*}{125} & \multirow[t]{2}{*}{900} & 1513 & 1.68 & 0.22 & 22,000 & 53,800 \\
\hline & & & 1315 & 1.46 & 0.07 & 22,000 & 47,000 \\
\hline
\end{tabular}




\section{DEPTH OF SUBSURFACE LAYERS}

REFRACTION METHOD

Velocities, strata (1) $=V_{1}$

$$
\text { strata (2) }=V_{2}
$$

Wave paths $S-R$

$S A B R$

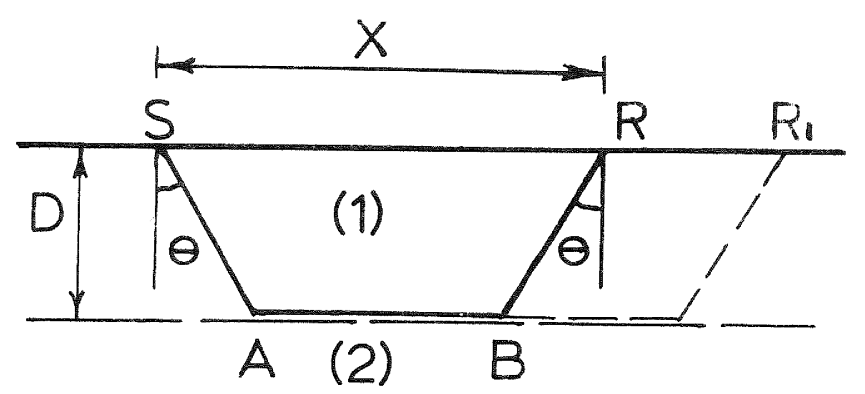

Travel time

(1) path $S-R=\frac{X}{V_{1}}=T_{1}$

(2) path $S A B R$

$$
T_{2}=\frac{2 D \sec \theta}{V_{1}}+\frac{X-2 D \tan \theta}{V_{2}}
$$

For minimum time

$$
\frac{d T_{2}}{d \theta}=\frac{2 D \sin \theta}{V_{1} \cos \theta}-\frac{2 D \sec ^{2} \theta}{V_{2}}=0
$$

Hence $\sin \theta=\frac{V_{1}}{V_{2}}$

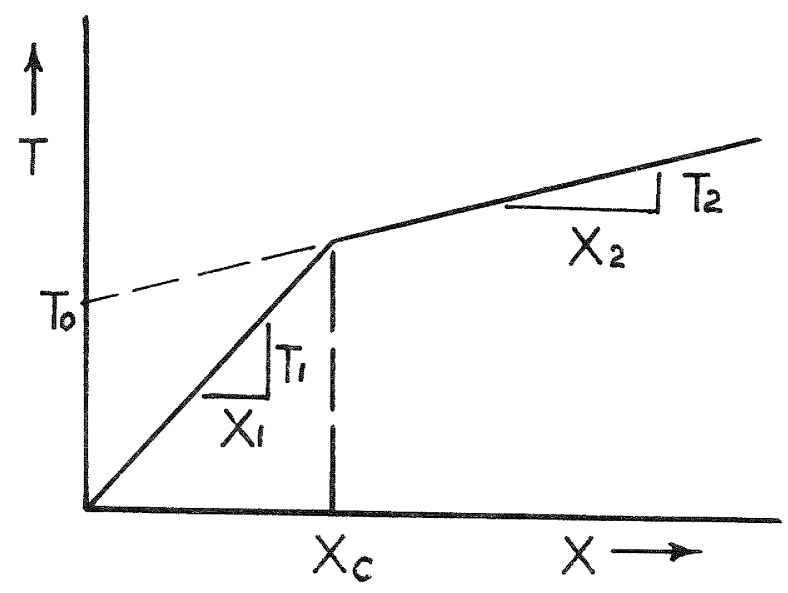

$$
\begin{aligned}
& V_{1}=\frac{X_{1}}{T_{1}} \\
& V_{2}=\frac{X_{2}}{T_{2}}
\end{aligned}
$$

For $\quad T_{1}=T_{2}$

$$
X_{c}=2 D\left[\frac{V_{2}+V_{1}}{V_{2}-V_{1}}\right]^{\frac{1}{2}} \quad \therefore D=\frac{X_{c}}{2}\left[\frac{V_{2}-V_{1}}{V_{2}+V_{1}}\right]^{\frac{1}{2}}
$$




\section{DEPTH OF SUBSURFACE LAYERS}

\section{REFLECTION METHOD}

For path SOR

$$
L=\left(4 D^{2}+X^{2}\right)^{\frac{1}{2}}
$$

Travel time

$$
\begin{aligned}
T & =\frac{L}{V} \\
\therefore \quad T^{2} & =\frac{4 D^{2}+X^{2}}{V^{2}}
\end{aligned}
$$

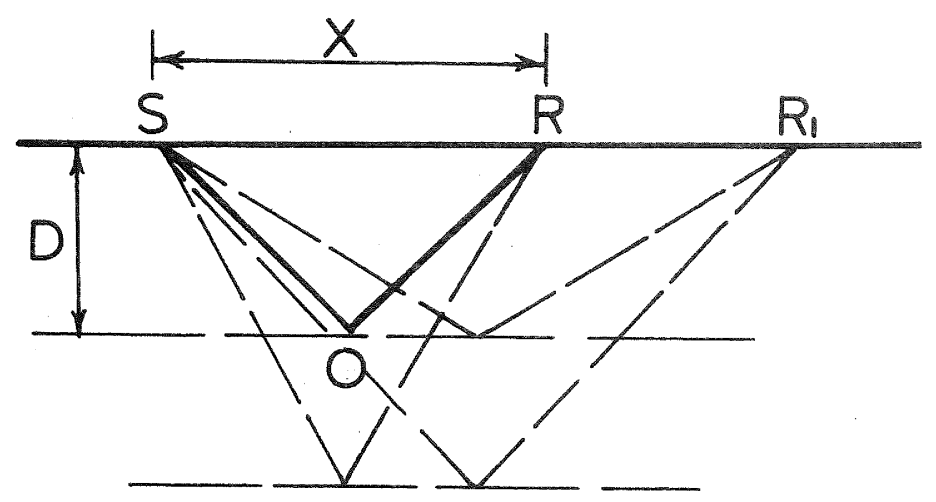

At $X=0$

$$
T_{0}=\frac{4 D^{2}}{V^{2}}
$$

Hence $D^{2}=\frac{T_{0} V^{2}}{4}$

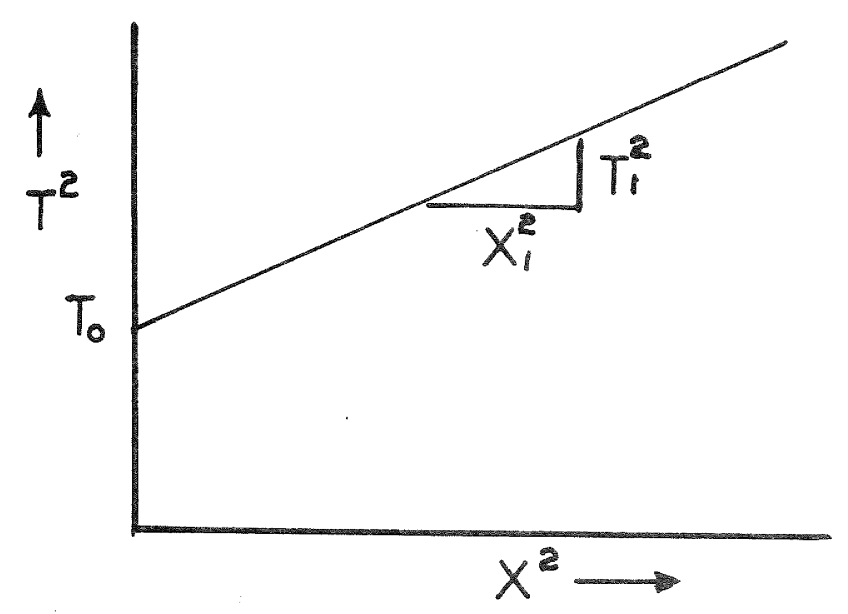

$$
\frac{d\left(T^{2}\right)}{d\left(X^{2}\right)}=\frac{1}{V^{e}} \quad V=\left(\frac{X_{1}^{2}}{T_{1}^{2}}\right)^{\frac{1}{2}}
$$




\section{MODIFIED REFLECTED WAVE VELOCITY}

Assumptions

(1) S wave velocity for layer is $V_{1}=V_{3}$ (measured)

(2) Pwave velocity is $V_{2}$

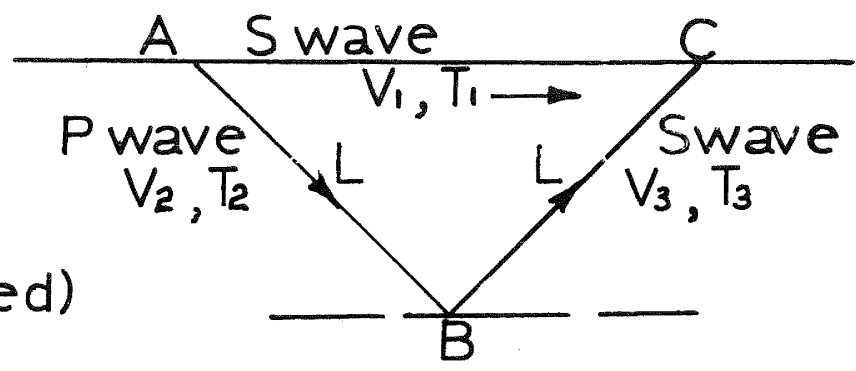

(3) P wave reflects as S wave

(4) 'Average' velocity on path $A B C$ is $V_{4}$ (measured)

(5) Corresponding travel times are $T_{1} T_{2} T_{3}: T_{4}=T_{2}+T_{3}$

Pwave path $L=V_{2} T_{2}=V_{3} T_{3}$

$$
\begin{aligned}
& =V_{1} T_{3} \\
T_{2} & =\frac{V_{1} T_{3}}{V_{2}}
\end{aligned}
$$

'Average' velocity $V_{4}=\frac{2 L}{T_{2}+T_{3}}$

$$
=\frac{2 V_{1} T_{3}}{\frac{V_{1} T_{3}}{V_{2}}+T_{3}}=\frac{2 V_{1} V_{2}}{V_{1}+V_{2}}
$$

so $\underline{P \text { wave velocity } V_{2}}=\frac{V_{1} V_{4}}{2 V_{1}-V_{4}}$ 
Glenmore Brickwork: Christchurch.

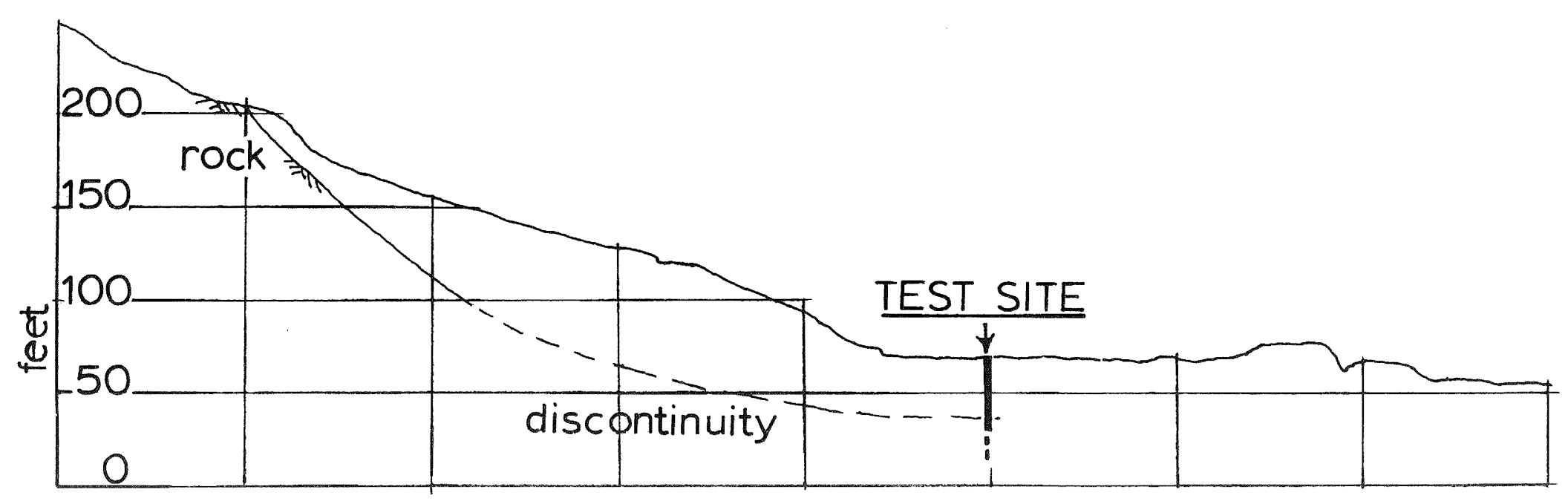

CROSS SECTION NN.12 GEOLOGICAL SURVEY (DSIR) 1966

scale $1^{\prime \prime}=100^{\prime}$

FIG Nํ. 1

$\vec{\infty}$ 
GLENMORE BRICKWORKS TEST SEQUENCE

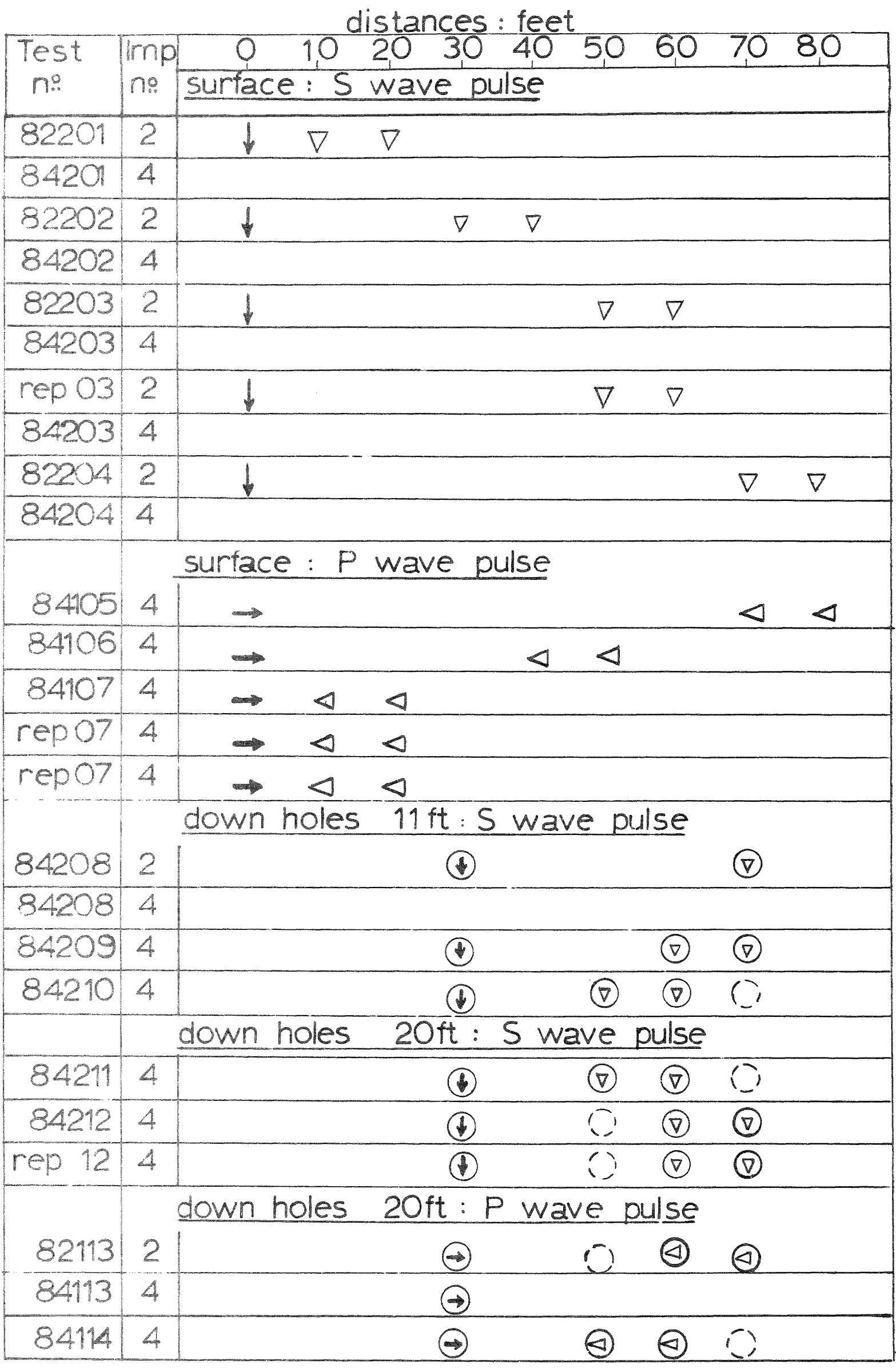


DEPTH PROFILE of Hole at $70 \mathrm{ft}$

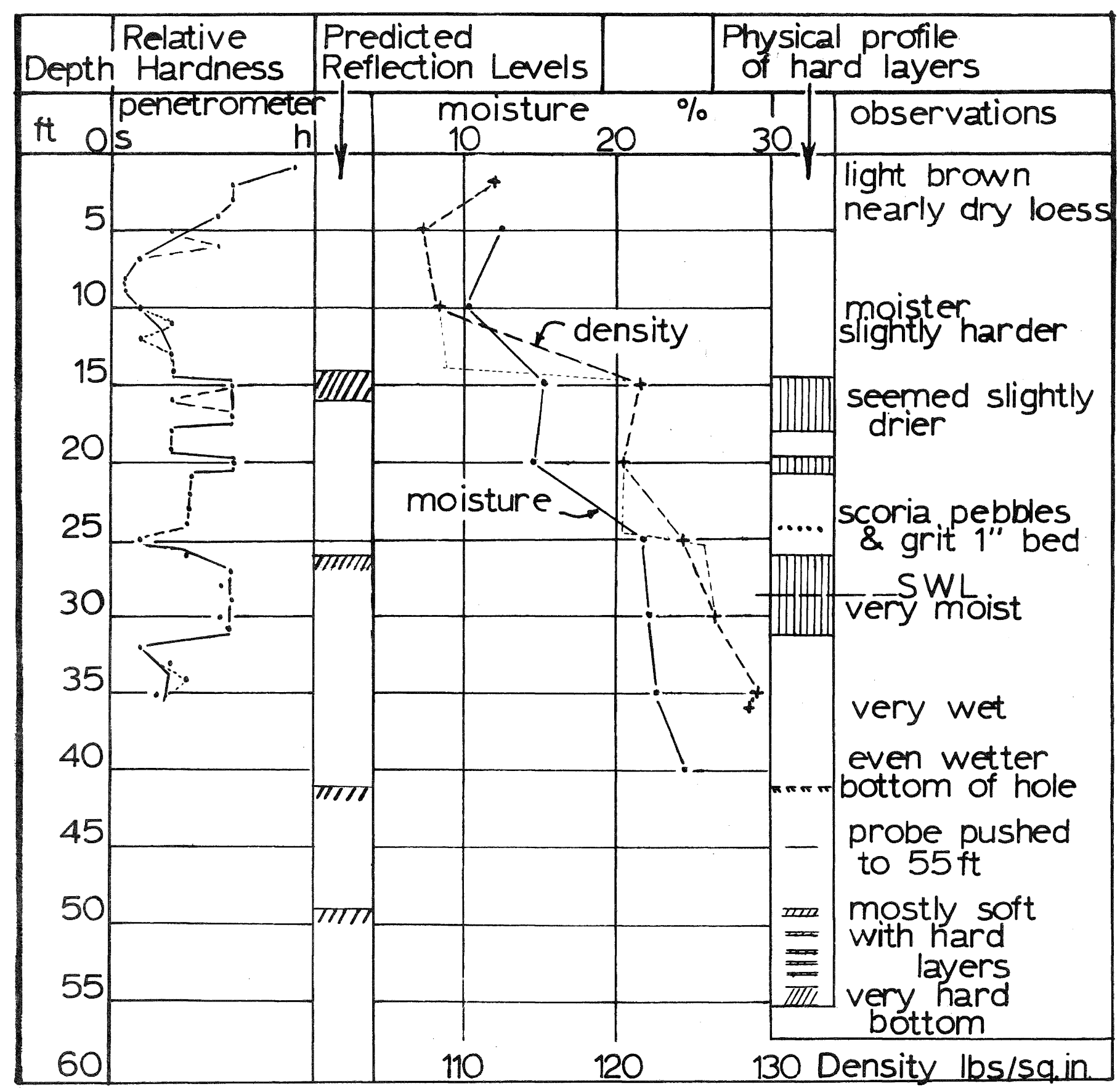

FIG № 3 
Ringing response from a small impact

总

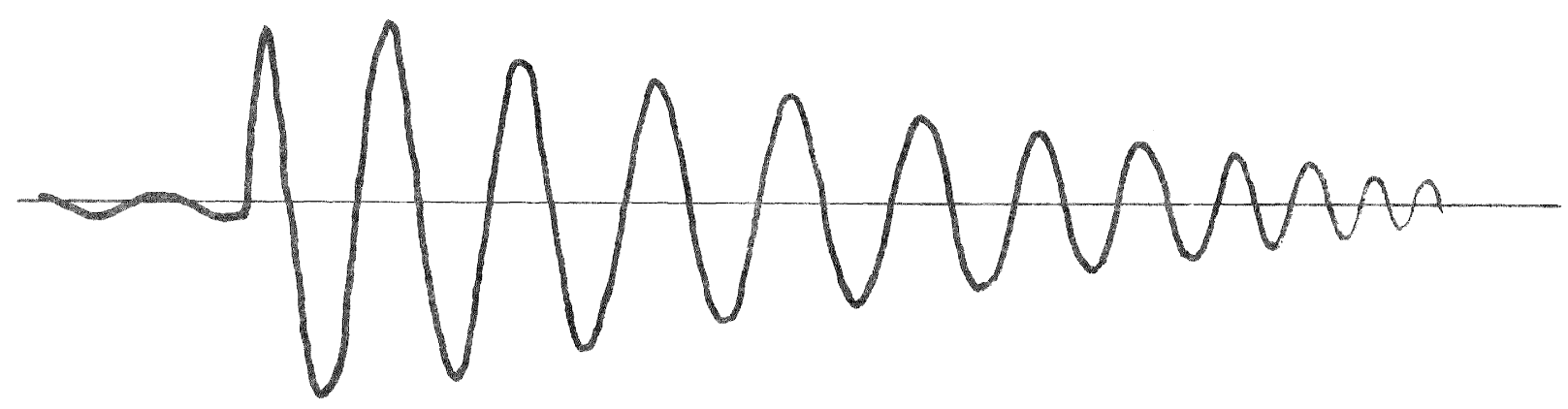

$100 \mathrm{cms} / \mathrm{sec} \quad$ intervals $\frac{1}{100} \mathrm{sec}$

FIG Nㅇ. 4

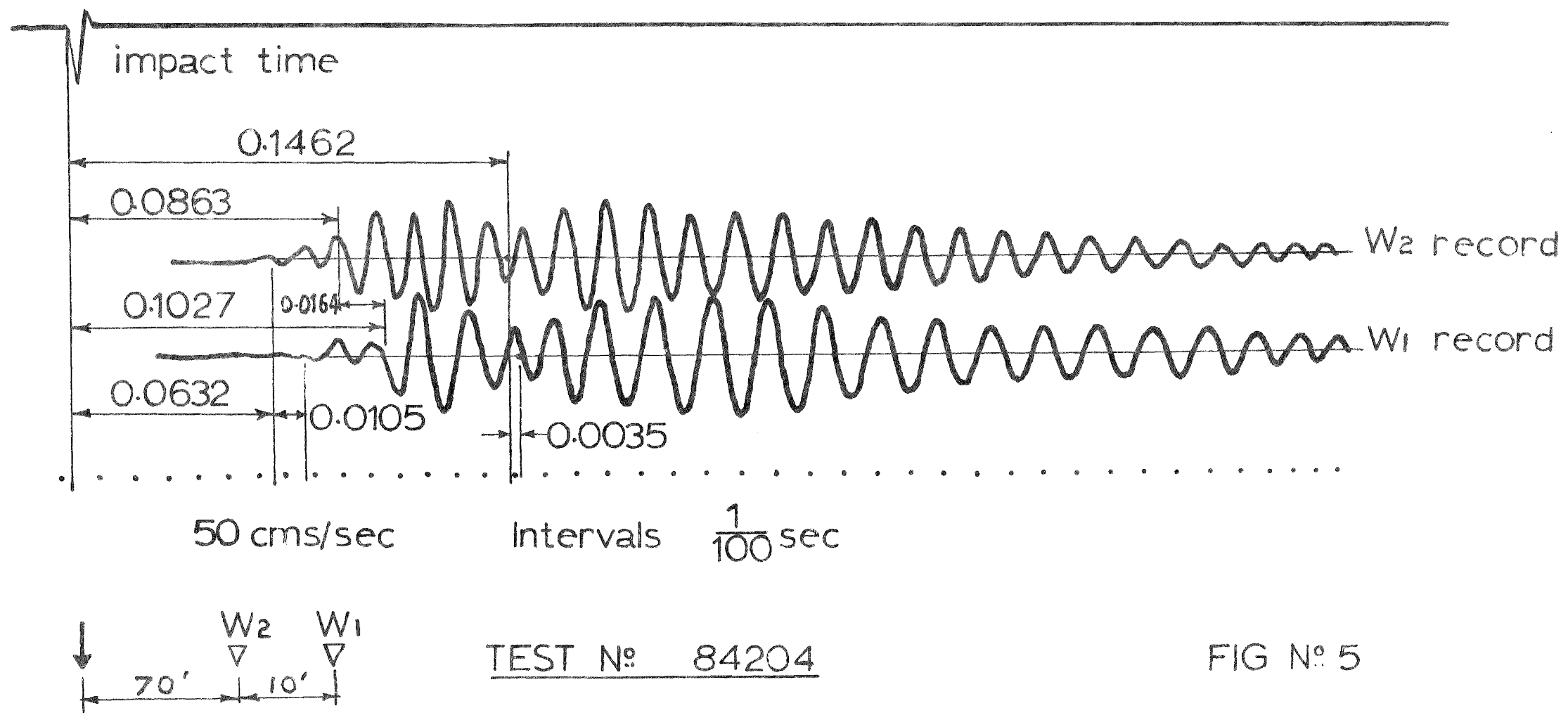


S WAVE PULSE: IMPACT 2: ON SURFACE

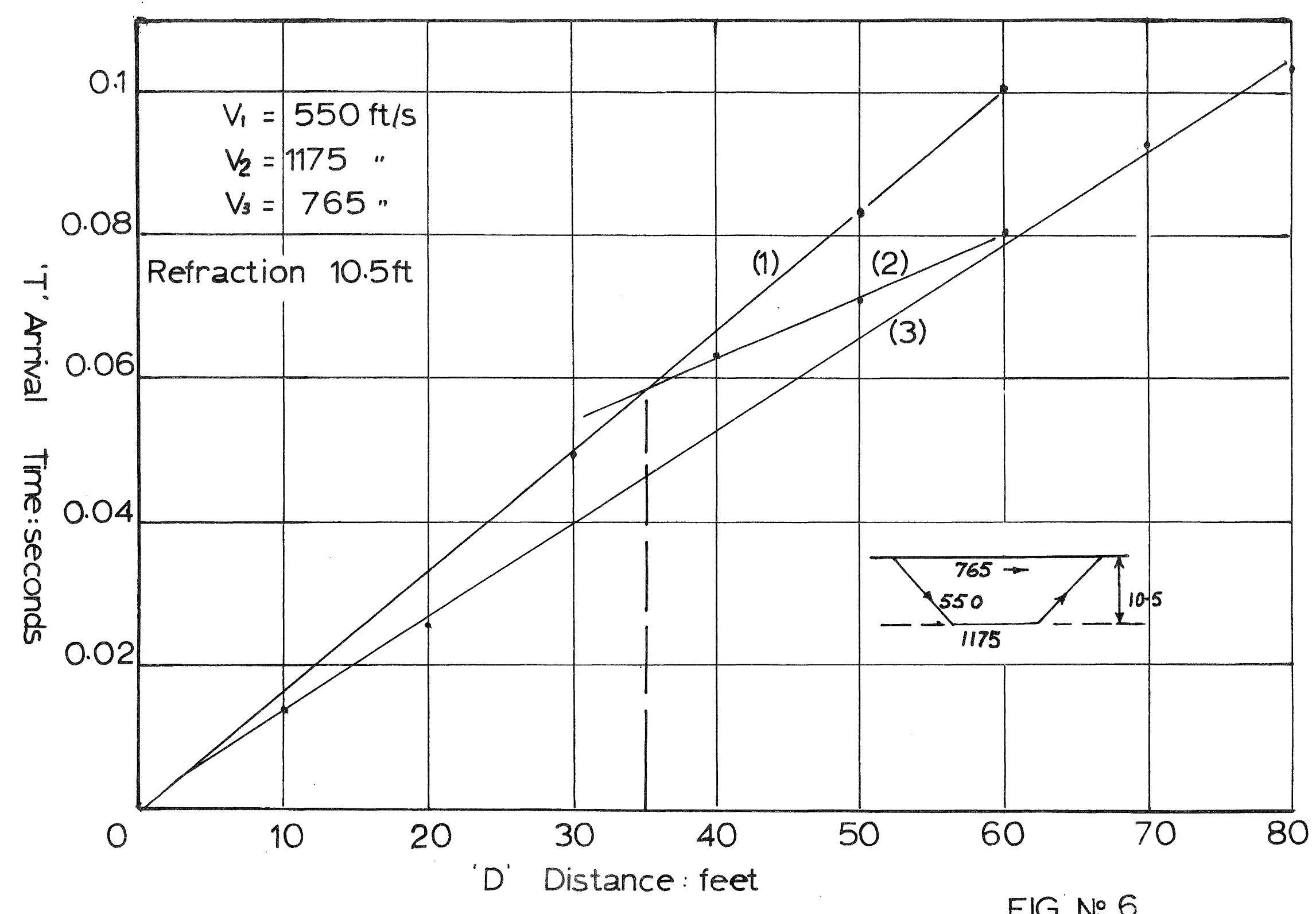

FIG № 6 


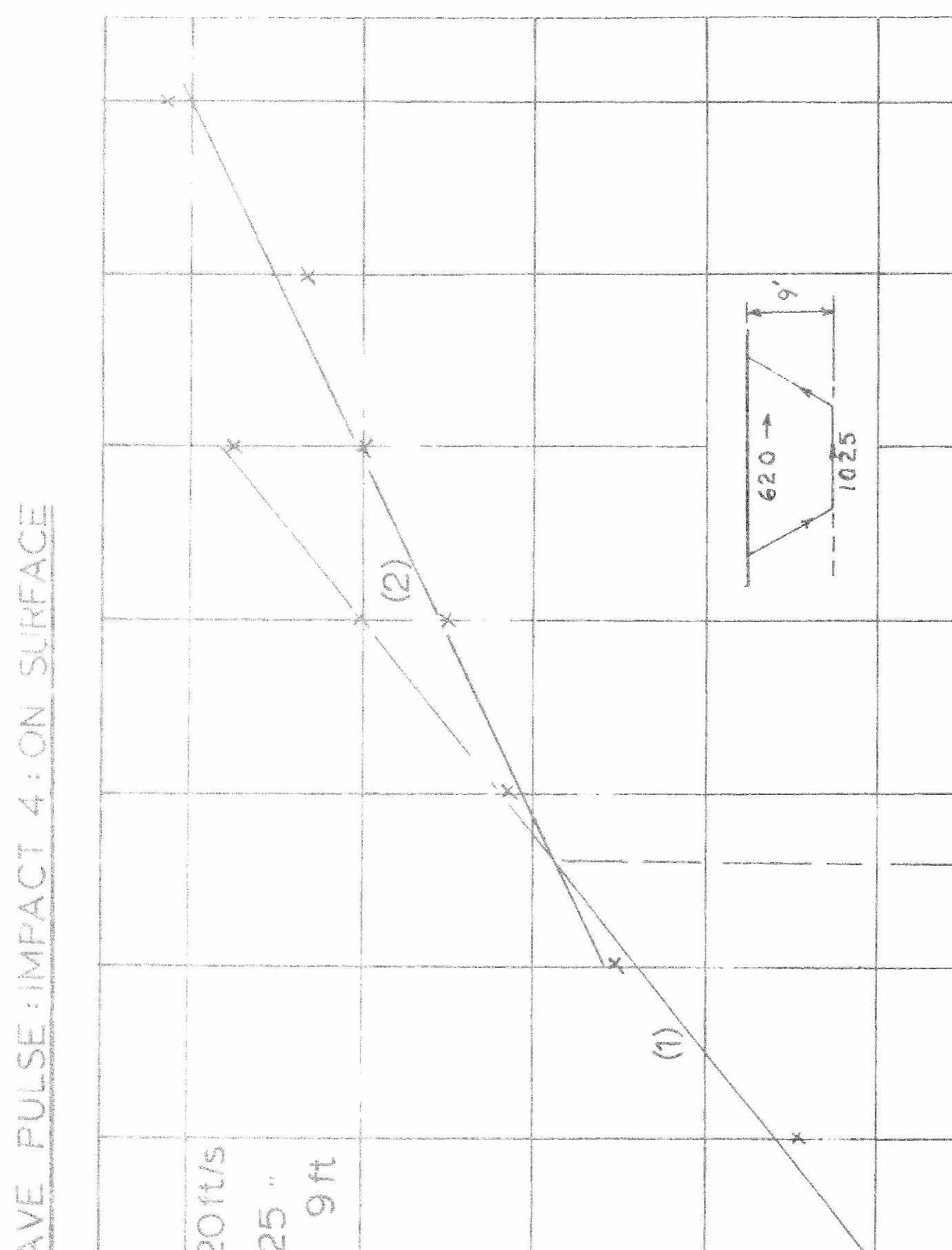




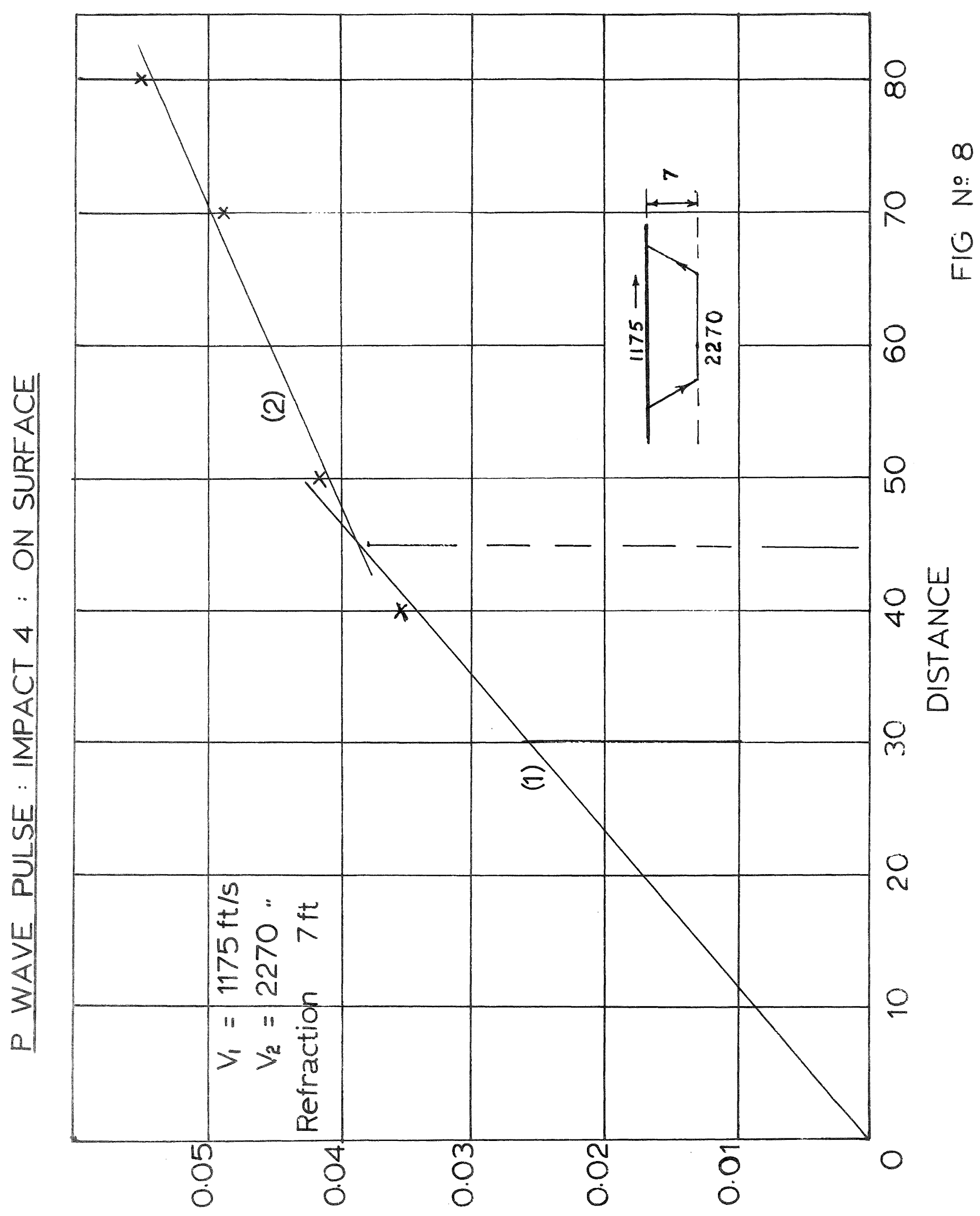

EIRST ARRIVAL TIMES : SECONDS ' $T$ ' 
S WAVE PULSE: IMPACT 2: ON SURFACE

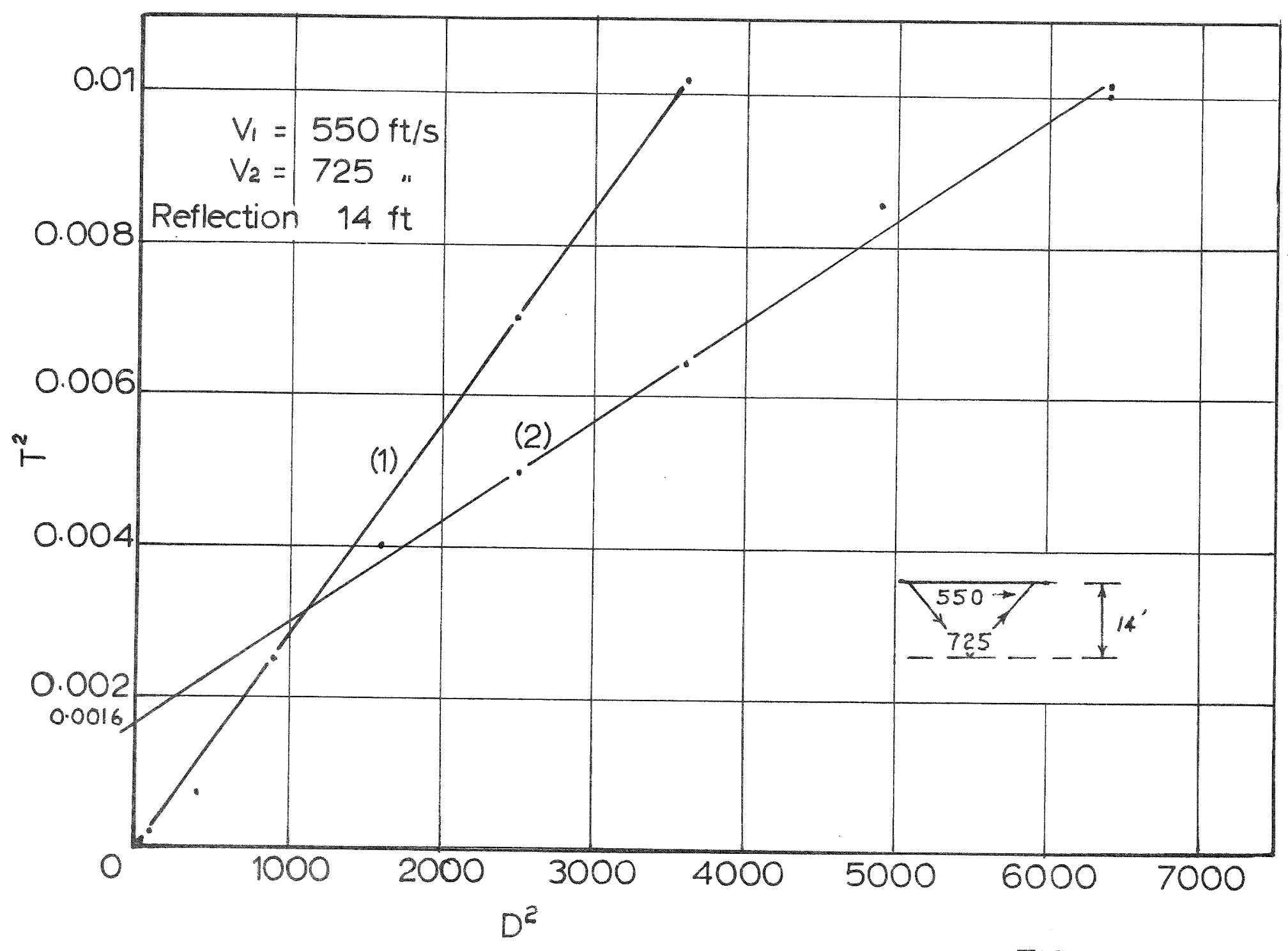

FIG № 9 
S WAVE PULSE: IMPACT 4: ON SURFACE

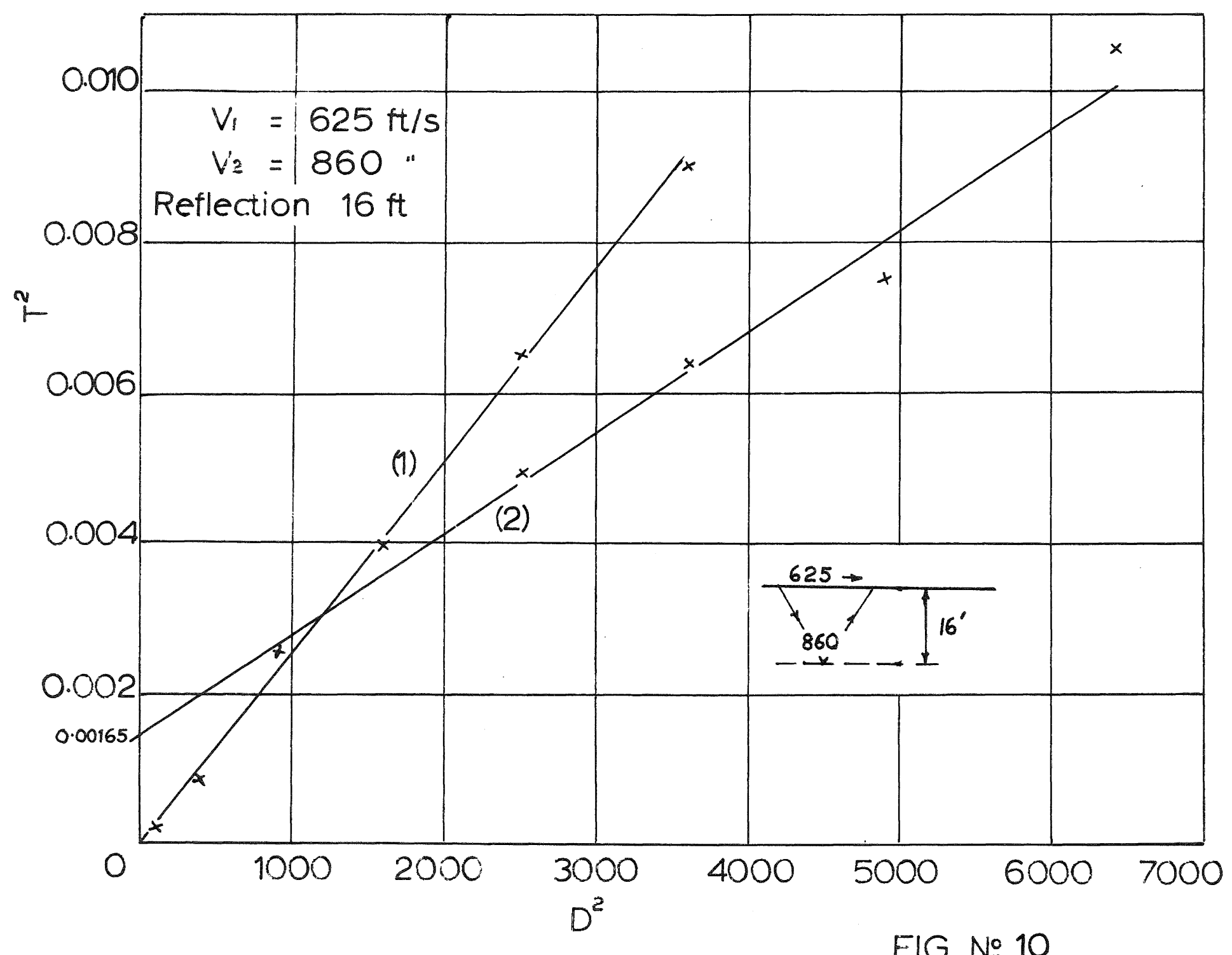

FIG № 10 
P WAVE PULSE: IMPACT 4: ON SURFACE

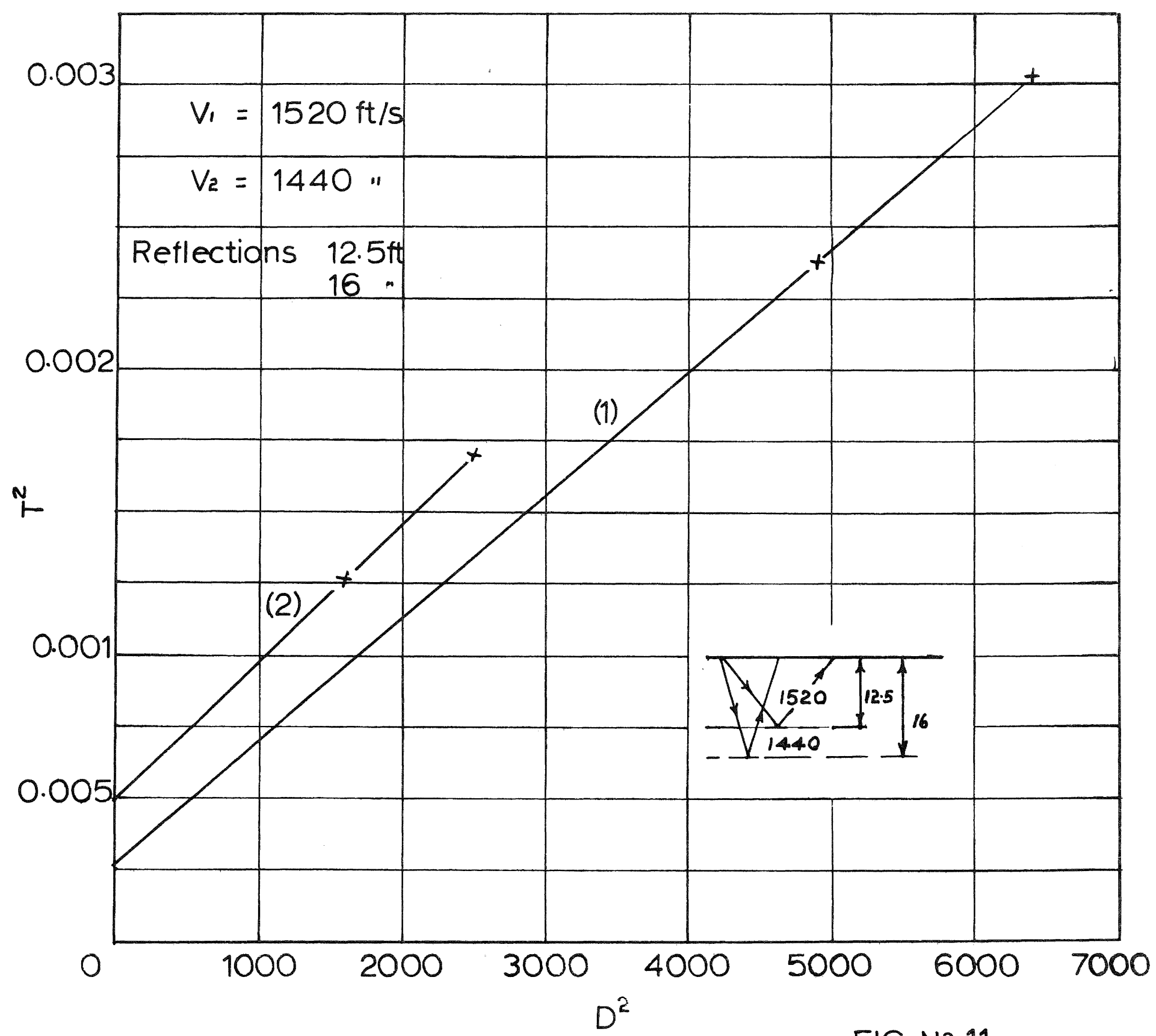

FIG Nㅇ 11 
P WAVE PULSE: IMPACT 4: LATE ARRIVALS: ON SURFACE

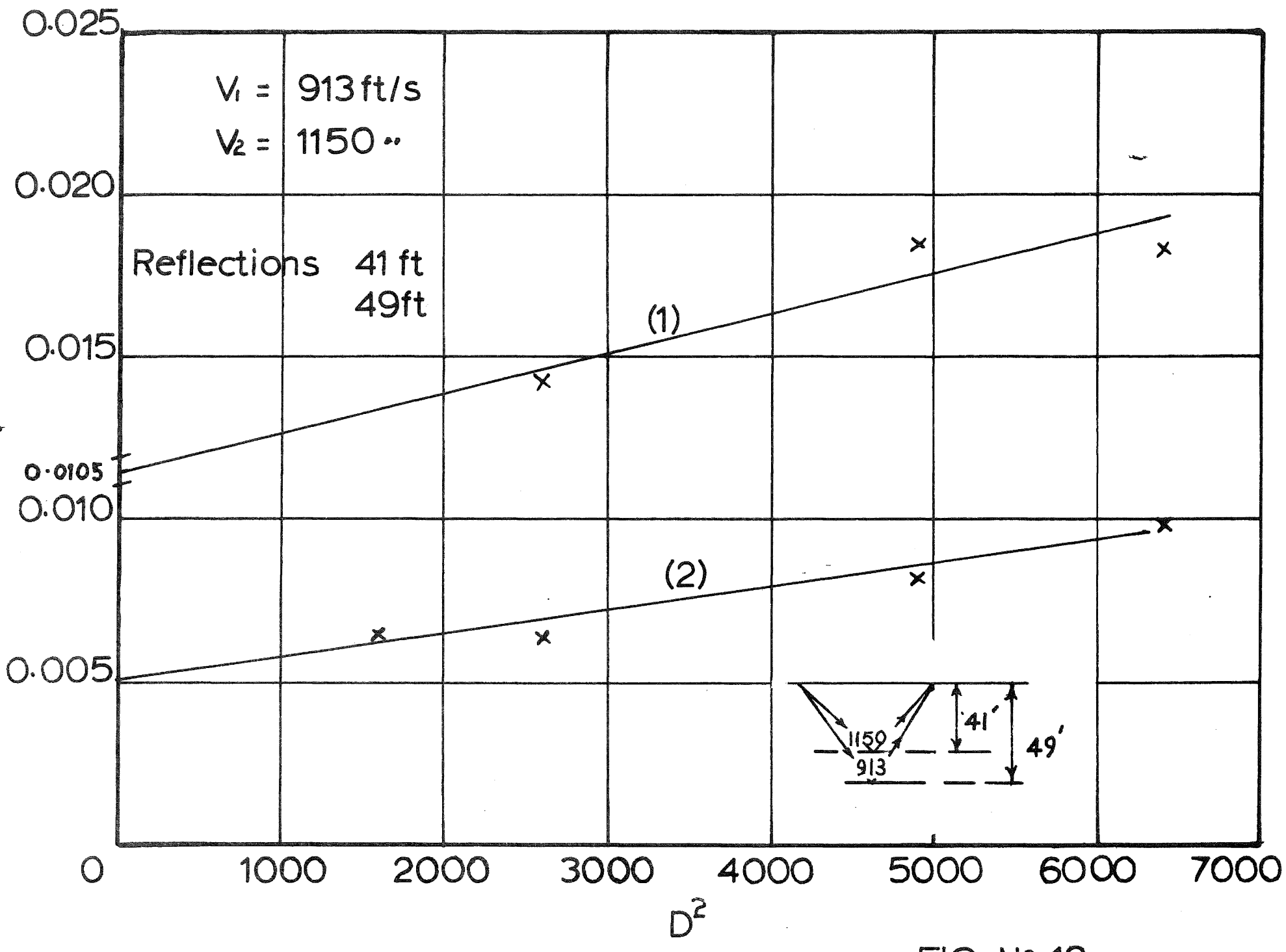

FIG NN 12 


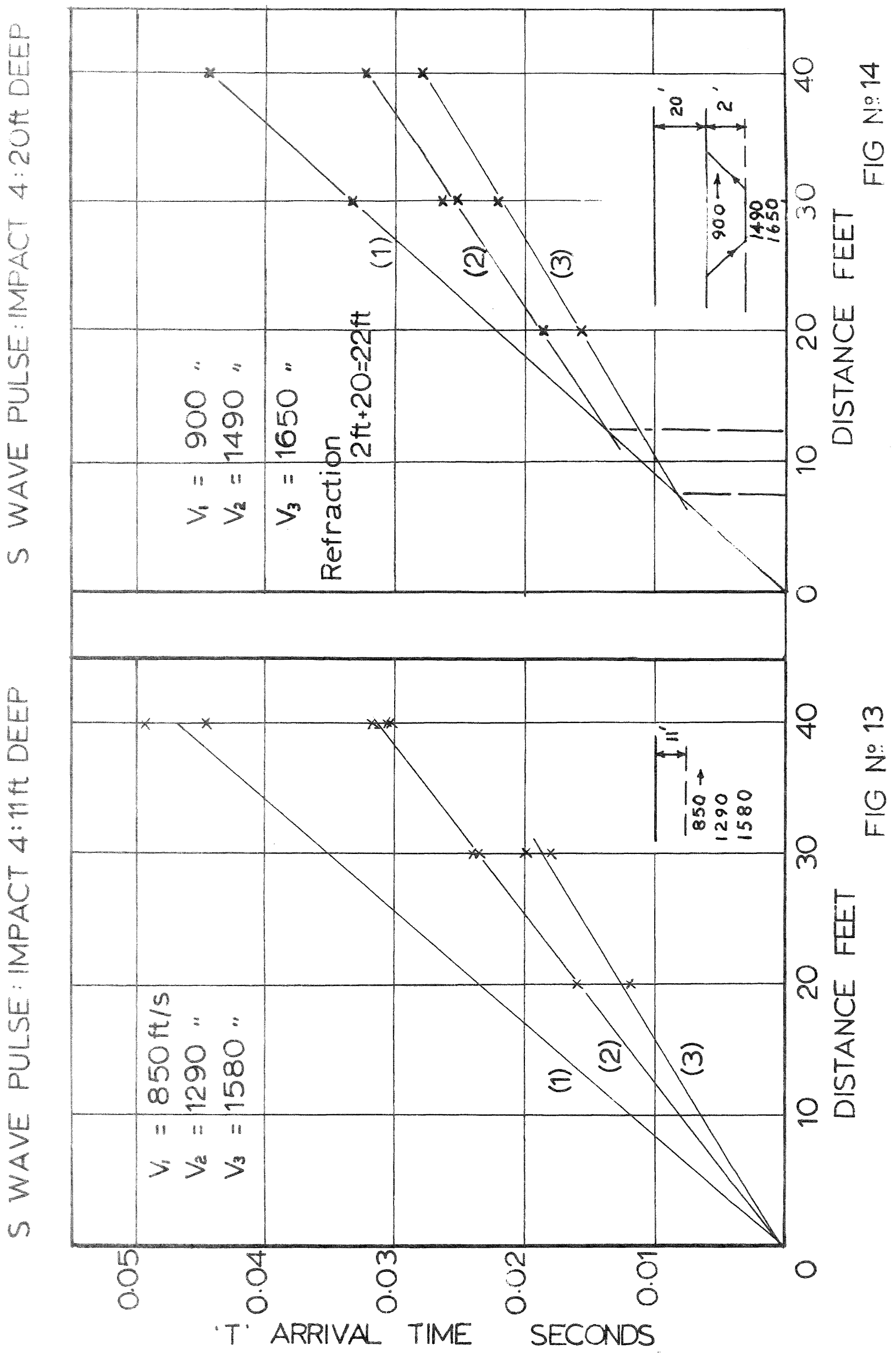


S WAVE PULSE: $11 \mathrm{ft}$ DEEP

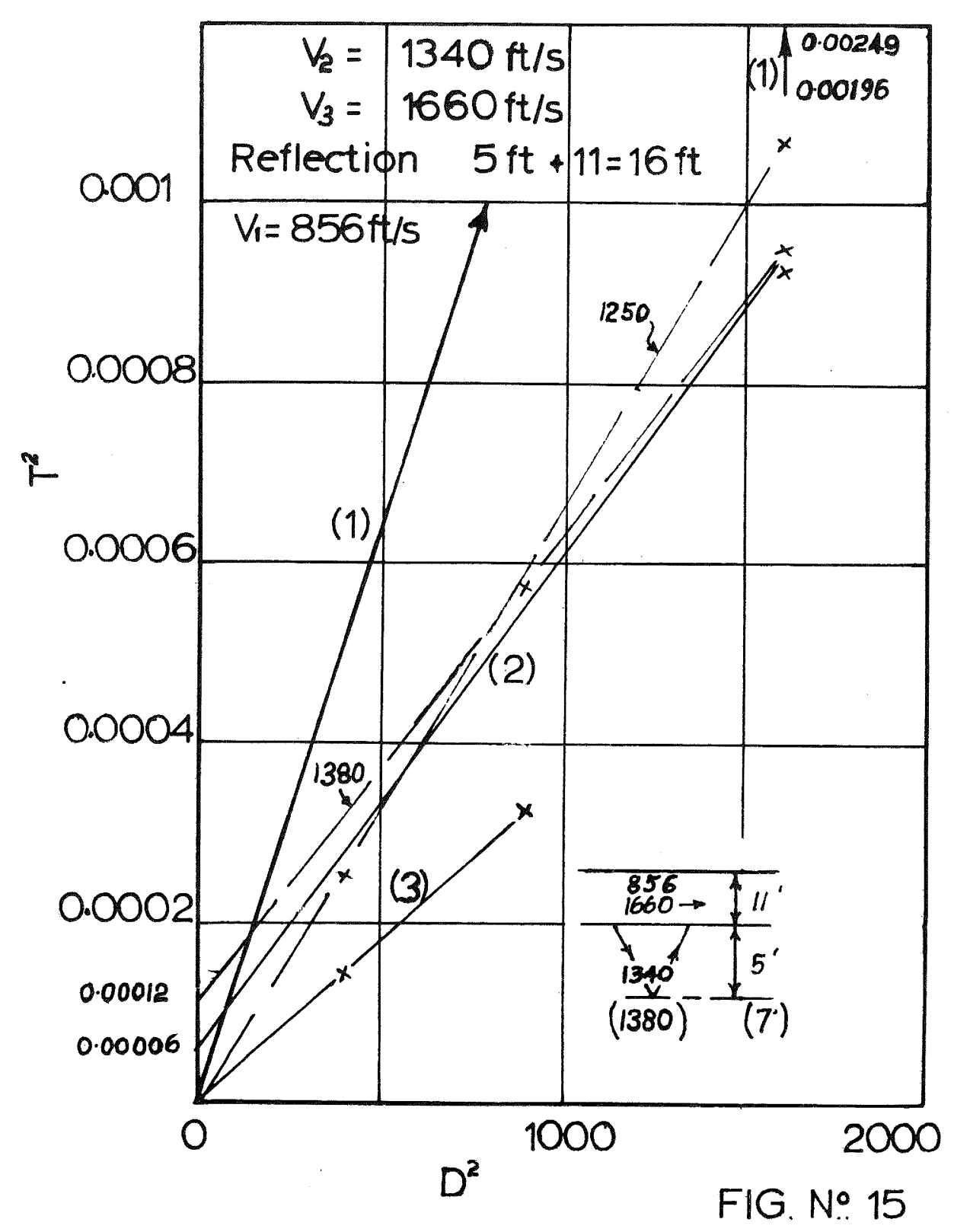

S WAVE PULSE:IMPACT 4:20ft DEEP

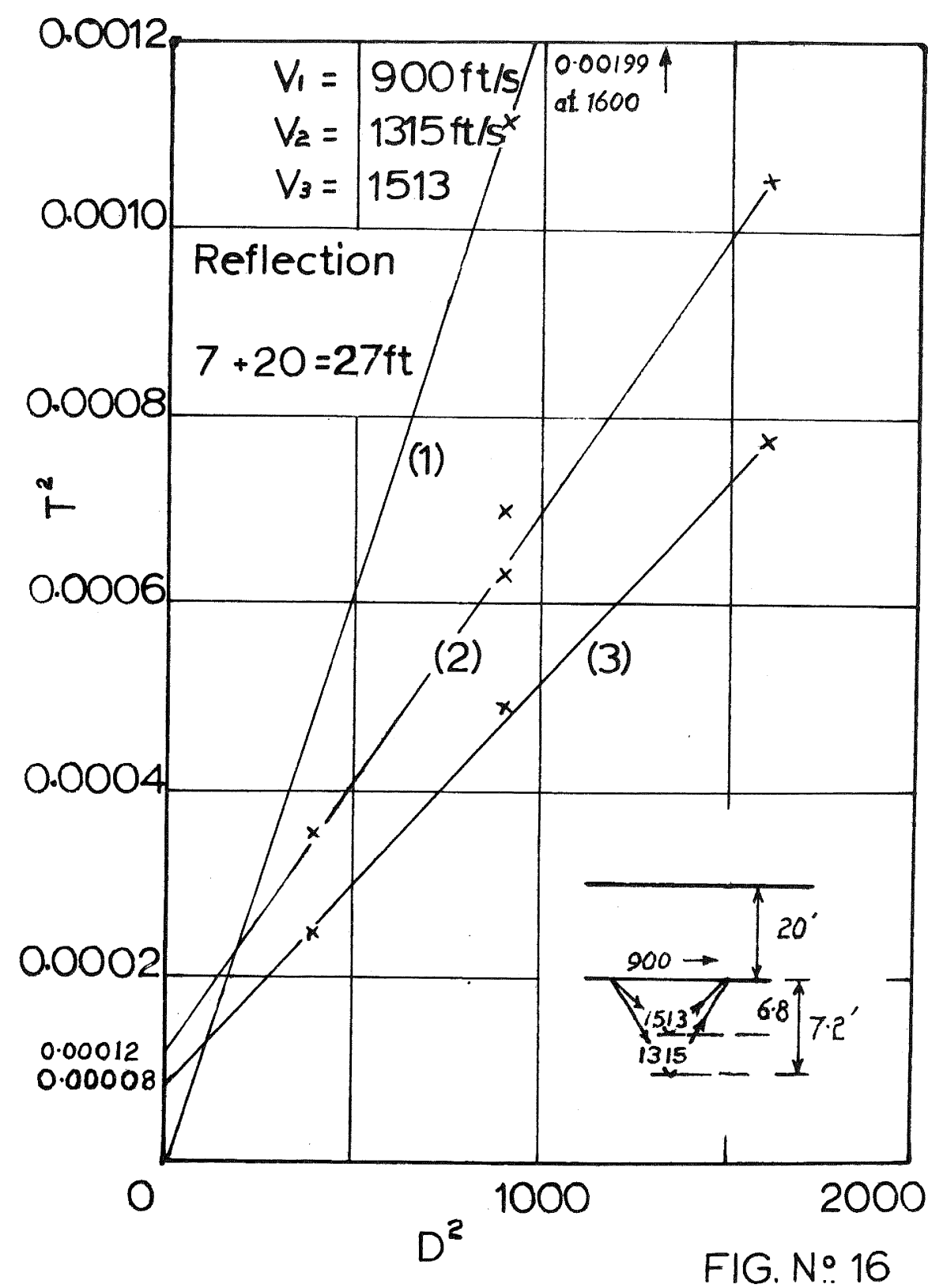



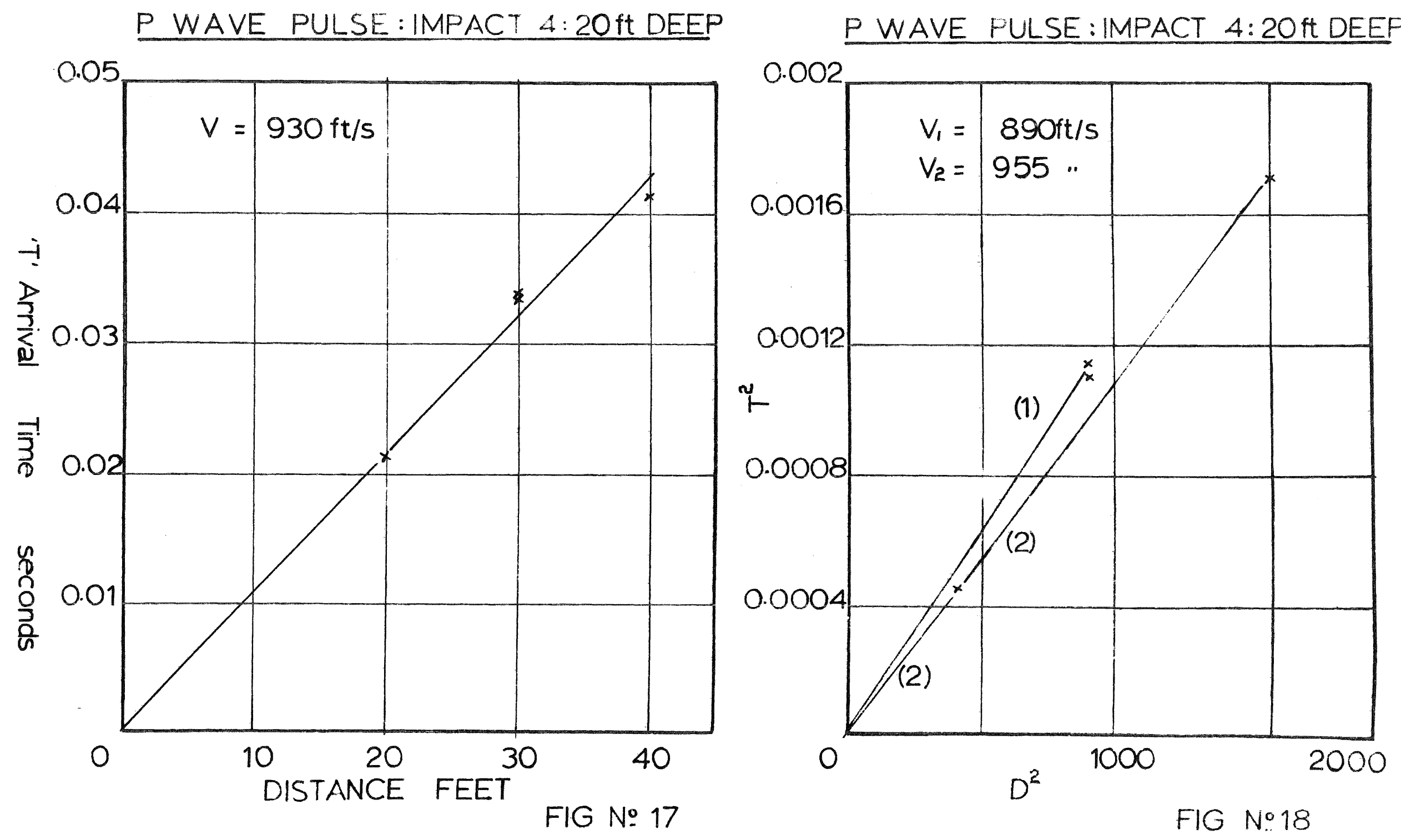


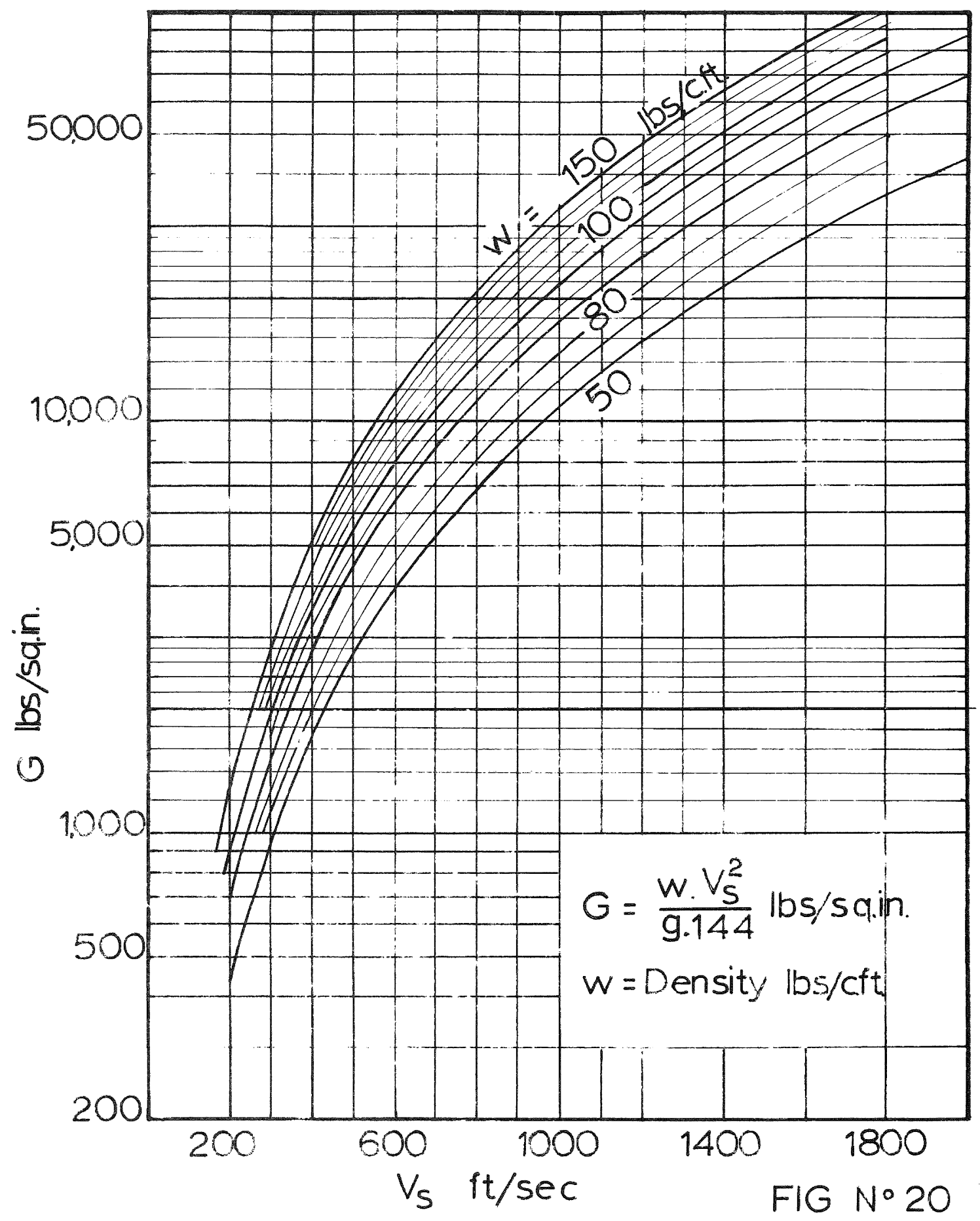




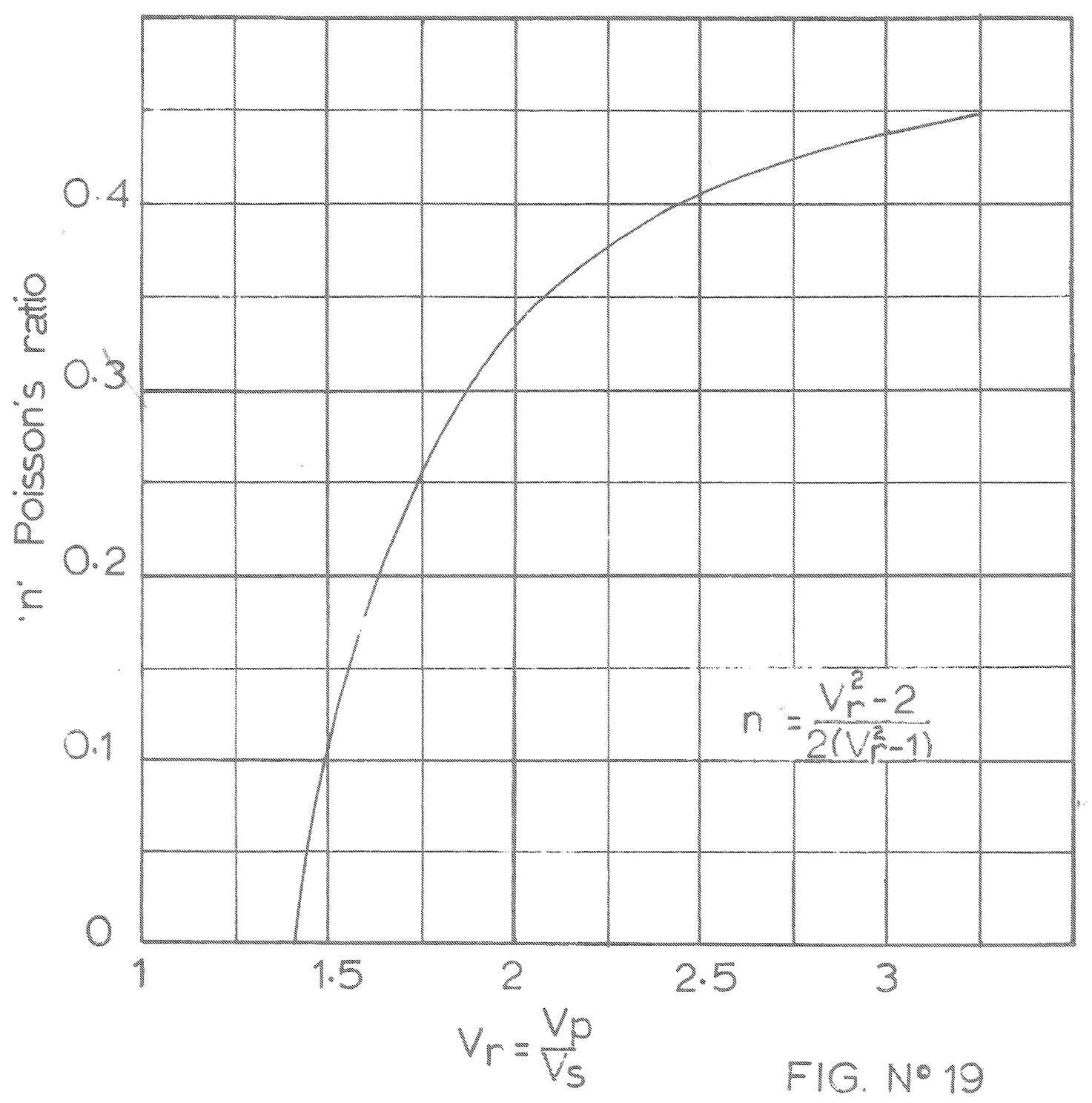

